\title{
وظيفة العلاقات العامة في الميدان السياحي
}

الدكتور ة: سامية بن عمر

جامعة الاغواط، الجزائر

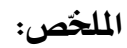

العلاقات العامة ظاهرة اجتماعية ظهرت مع وجود البشرية على الأرض وتطورت بتطور

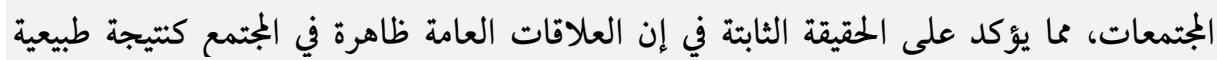
للاحتكاك الاجتماعى بين افراده وهيئاته، لذا نجد جل المؤسسات على إنى اختلاف العلاف أنوات أنواعها وإحجامها تستعين بها بهدف الحصول على رضى الجماهير وثقتهم فيهم وتأييدهم ، ومبحال

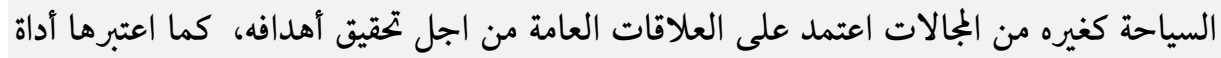

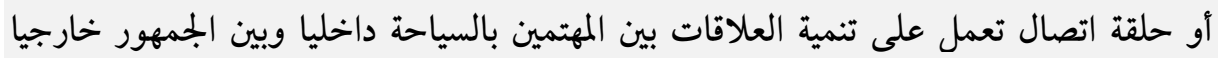

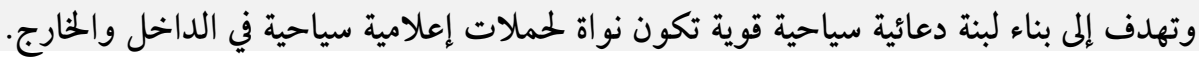

\section{Résumé:}

Les relations publiques sont un phénomène social apparu avec l'existence de l'homme sur terre. Elles se sont développées selon le rythme de chaque société. C'est le corollaire des contacts humains, à cause de cela toutes les institutions, quelles qu'elles soient les utilisent comme support ou outil pour gagner la confiance des gens; et le tourisme, tout comme les autres domaines, est fondé sur les relations publiques pour atteindre ses objectifs. Par conséquent, elles sont considérées tel un pont entre l'intérieur et l'extérieur du public afin d'établir une large publicité et de même, elles sont le noyau de toute campagne publicitaire. 


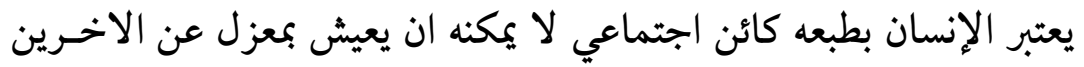

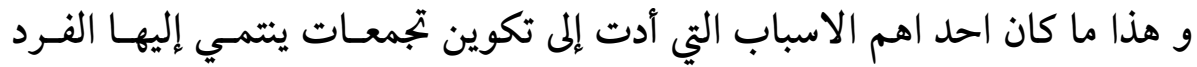

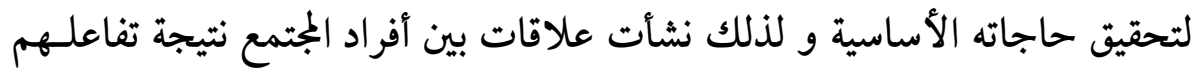

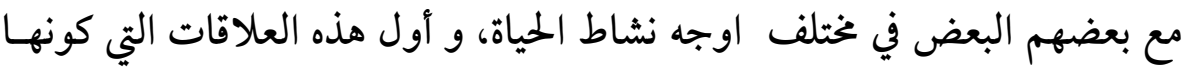

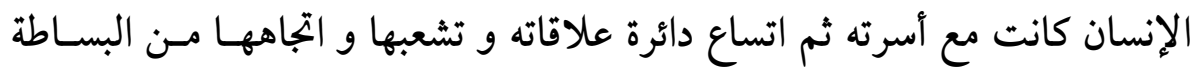

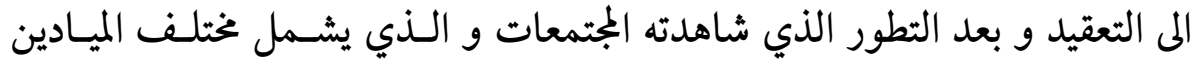

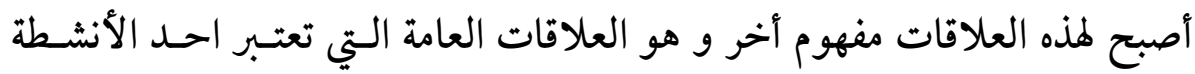

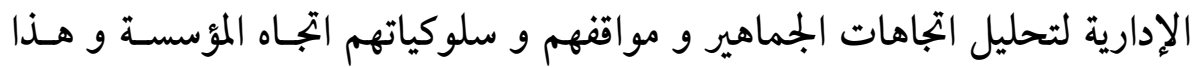

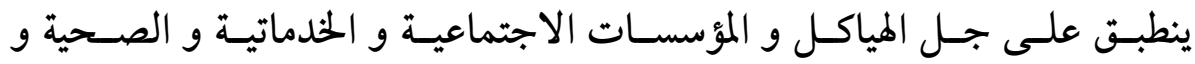

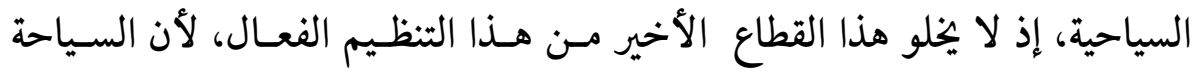

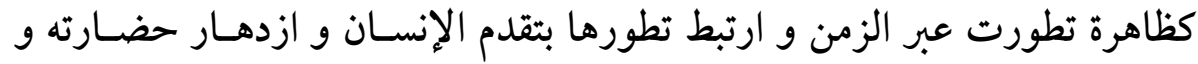

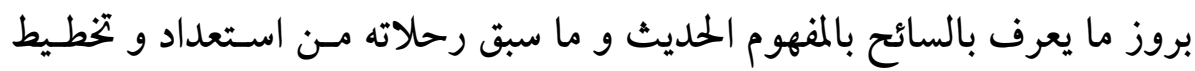

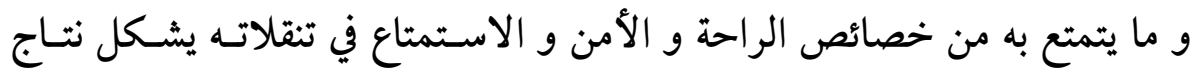
تراكمات حضارية و تفاعل أجيال متعاقبة من الرحالة و و السياح.

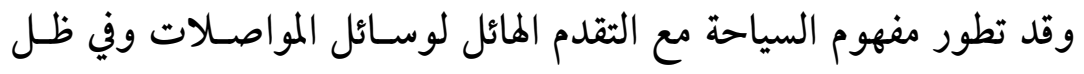

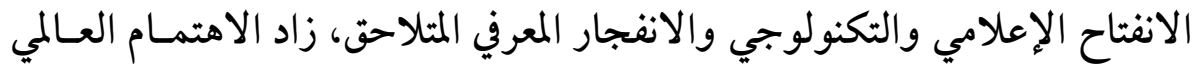

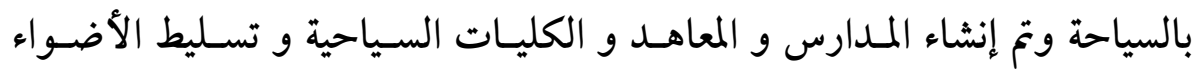

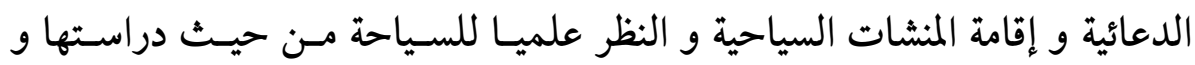

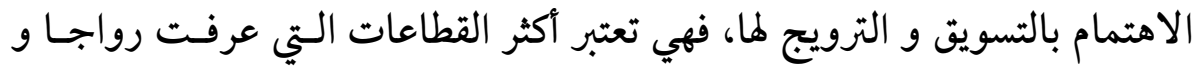

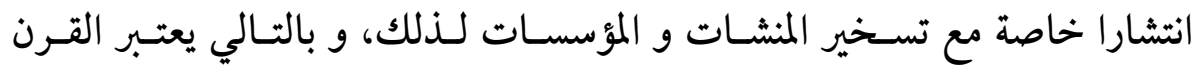

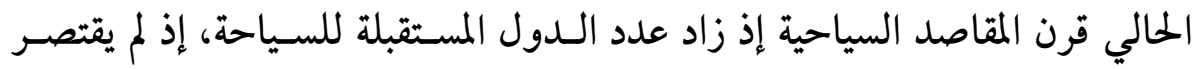

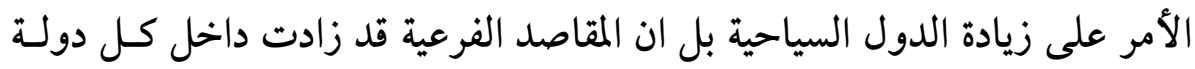

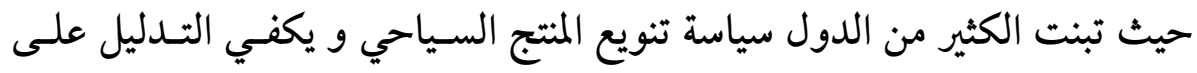


صحة هذا ان نلقي نظرة على ما تحقق في الجزائر من مقاصـد سـياحية زادت عـبر

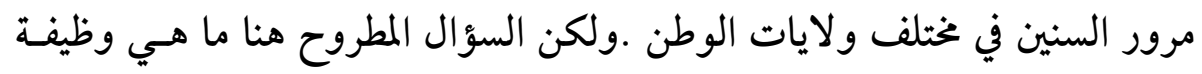
العلاقات العامة في الميدان السياحي؟ فئ.

أولا :مدخل نظري للعلاقات العامة:

أن العلاقات العامة ولدت بمولد الإنسان إذ أنها ظاهرة اجتماعية ظهرت

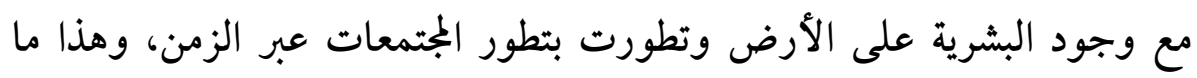

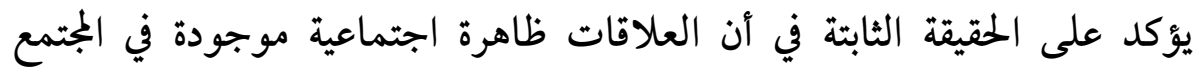

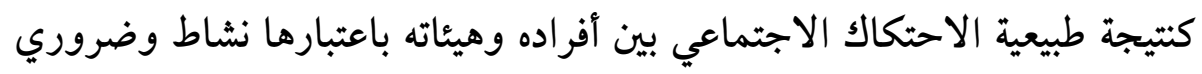
للإنسان في معاملاته مع المنظمات والهيئات المجودة في المجتمع. و يعتبر توماس ميفرسون "الرئيس الثالث للولايات المتحدة الأمريكية أول

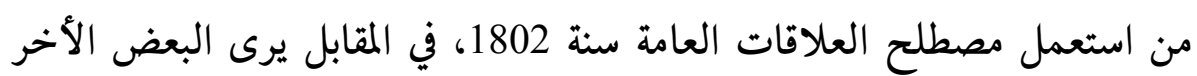

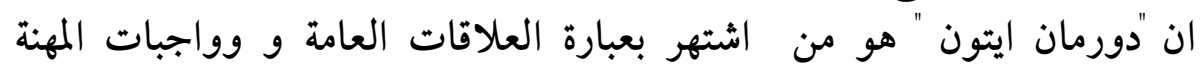

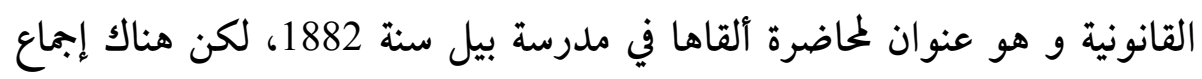

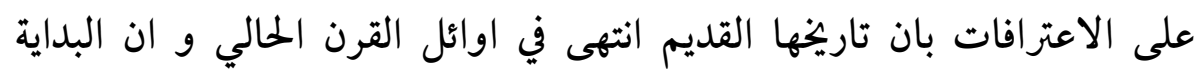

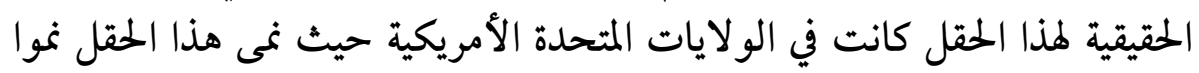

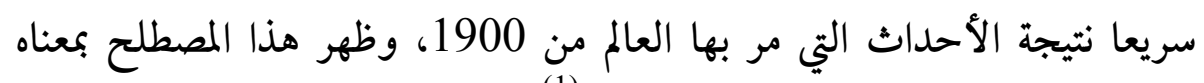
الحديث على يد الرائد "ايفي لي" التي مام بـ 1906 (1).

حيث شهدت العلاقات العامة تطورا ملحوظا اذ تزايد اهتمام المؤسسات

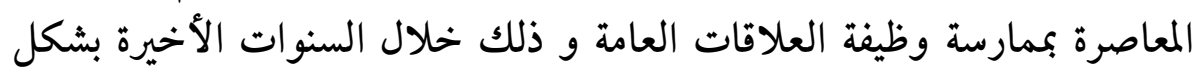

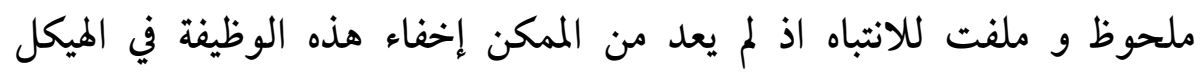

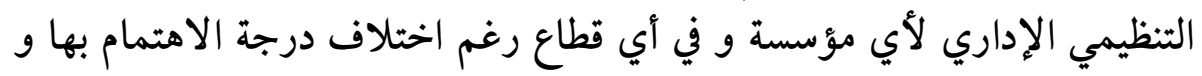

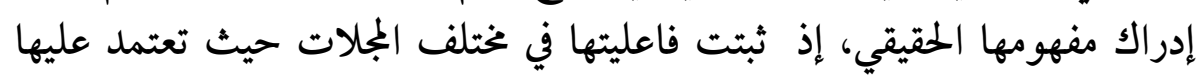

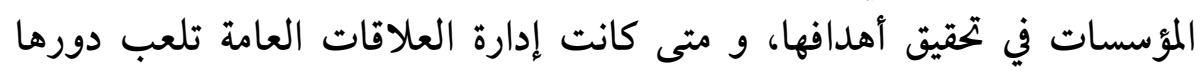

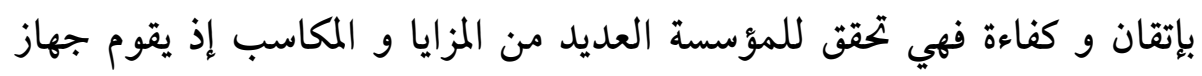

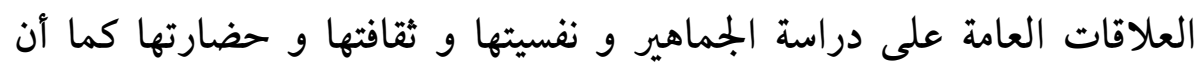


وظيفتها الأساسية تتمثل في المساعدة الايجابية على تحسين علاقة المنظمة بالجماهير

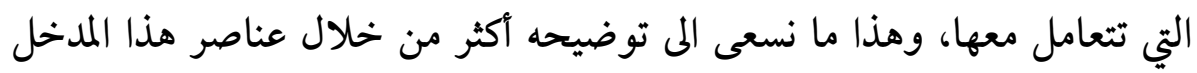

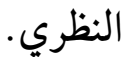
1

قبل الحديث عن تعريف العلاقات العامة نود أن نتطرق أولا إلى التعريف اللغوي للعلاقة وكذا عامة وهو كمايلي:

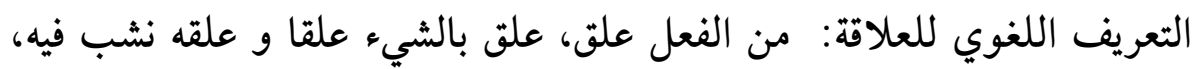

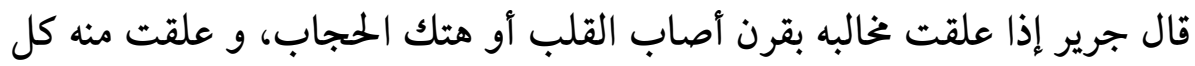

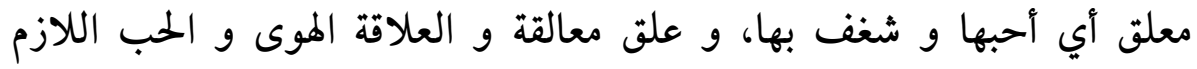

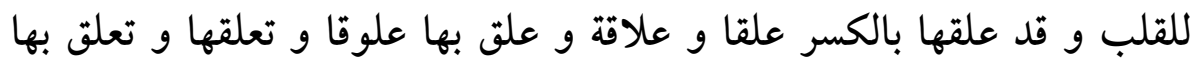

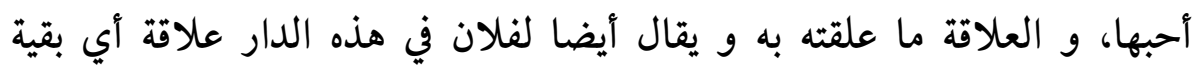

التعريف اللغوي لعامة: خلاف الخاصة، قال ثعلب سميت بذلك لأنها تعم البشر و العمم، العامة اسم للجميع (3).

أما من الناحية الاصطلاحية يختلف حسب المهمة الوظيفية للعلاقات

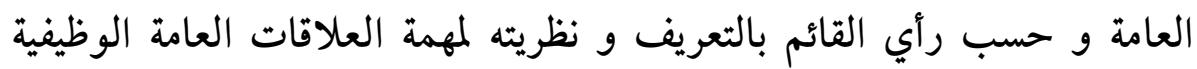

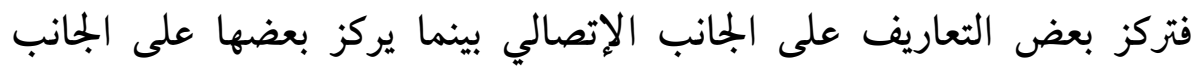

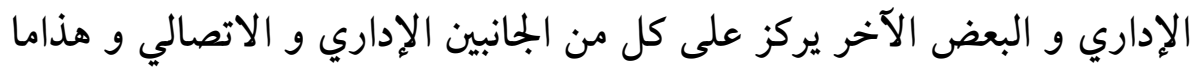
تتفق عليه معظم التعاريف.

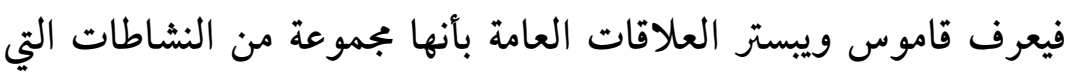

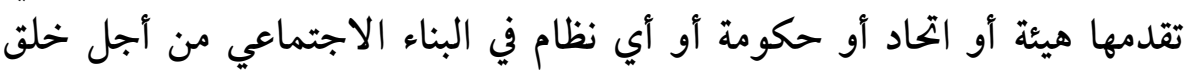

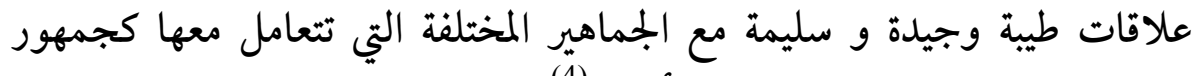

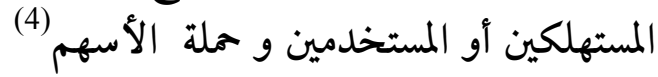


و أهم ما أشار إليه التعريف هو أنه لم يقصر العلاقات العامة على نوع من المهن

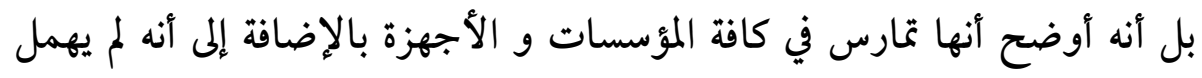
كلا من الجماهير الخارجية و الداخلية.

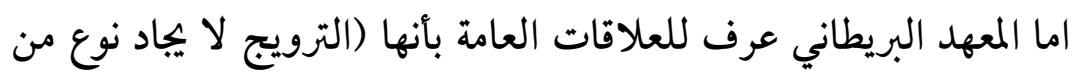

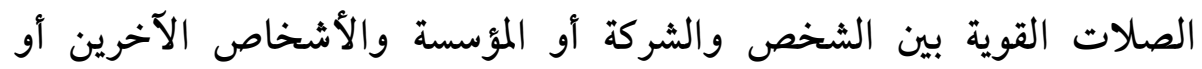

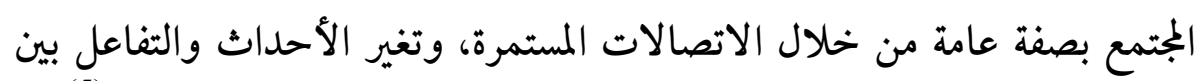
الأفراد والجماعات ثم تقيم ردود الفعل الناتجة عن هذا الاتصال ونات والتفاعل) (5) .

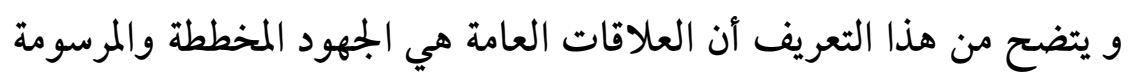
يقصد منها إقامة التفاهم المستمر بين المنظمة وجماهيرها. وفي تعريف مارستون (Marston) العلاقات العامة نشاط إداري يقوم على تقيم

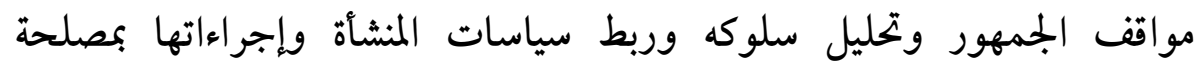

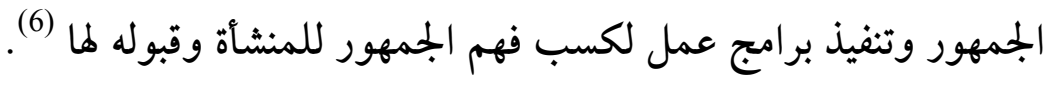

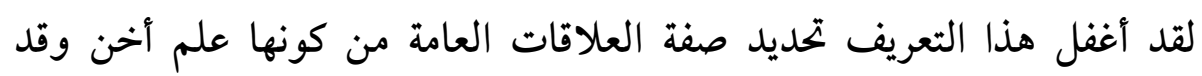
اعتبرها ضربا من ضروب النشاط الإنساني الذي تقوم به المؤسسة.

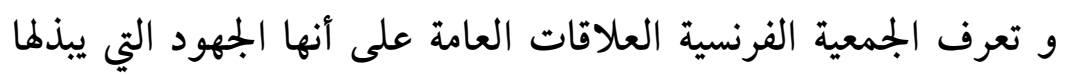

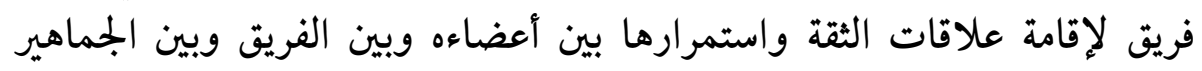

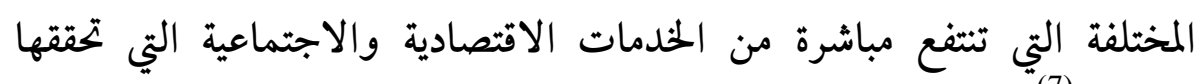
المؤسسة (7)

وهناك من عرفها بأنها فن الحصول على رضا الجماهير وثقتهم وتأييدهم

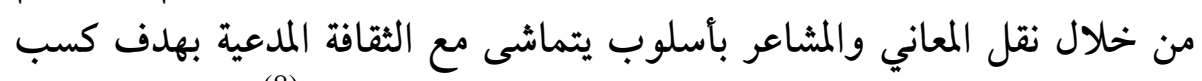

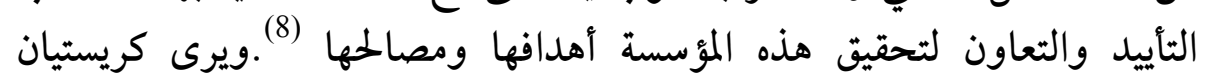

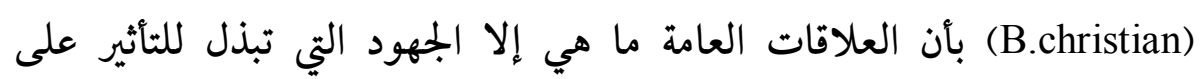

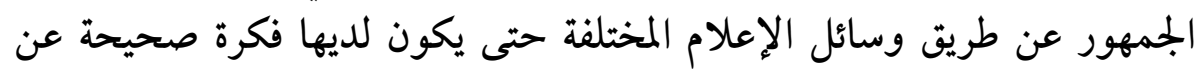

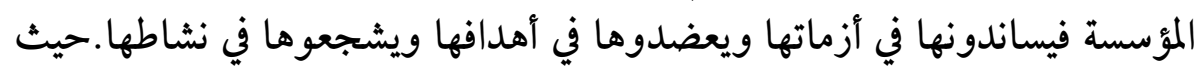


يؤكد هذا التعريف على أن هدف العلاقات العامة هو مساندة الجمهور وتأييده

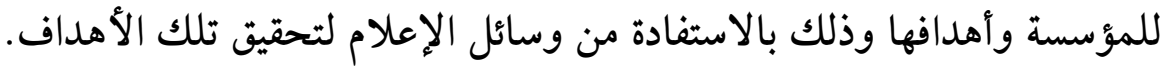

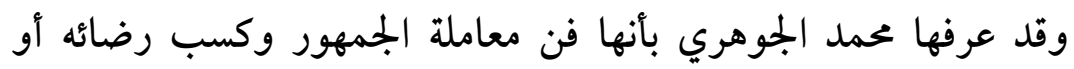

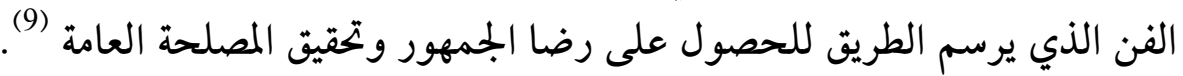
من الواضح أن هذا التعريف يركز على أن العلاقات العامة فن يحتاج إلى مهارة

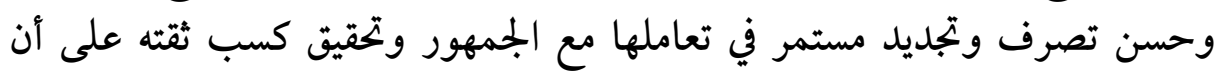

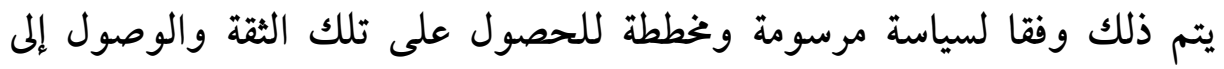
تحقيق مصلحة الجانبين. أما تعريف العلاقات العامة من منظور الإدارة فهي الوظيفة الإدارية التي

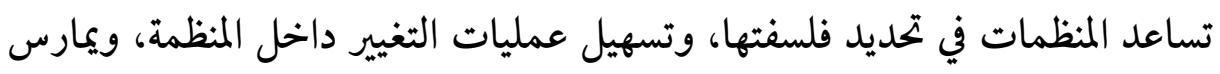

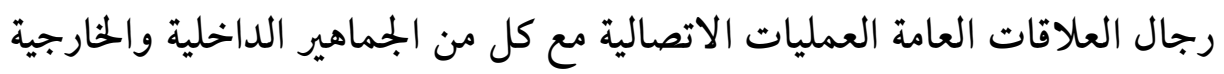

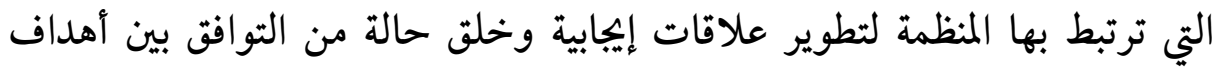

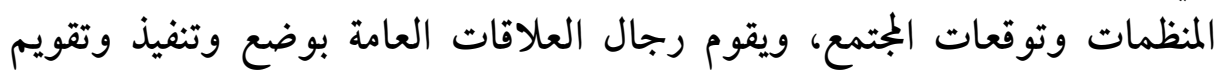

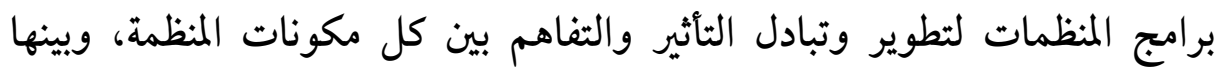
وبين المجتمع.

وثمة تعريف آخر يرى أن العلاقات العامة هي الوظيفة التي تحدد وتبني

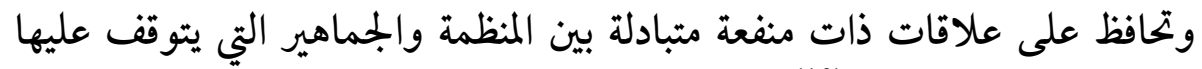

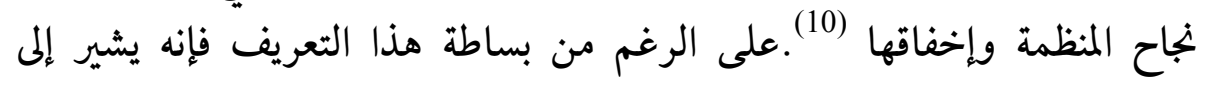

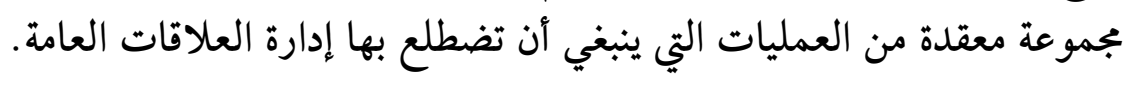

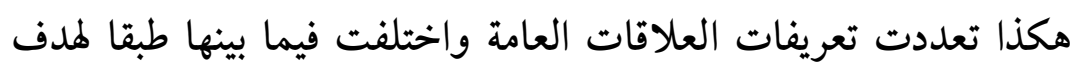

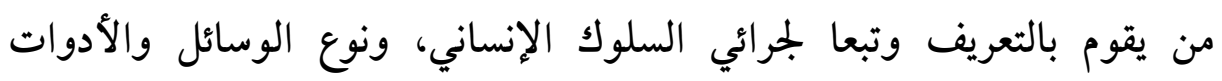

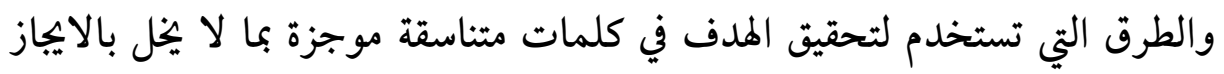

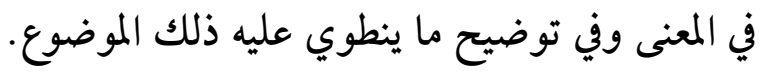




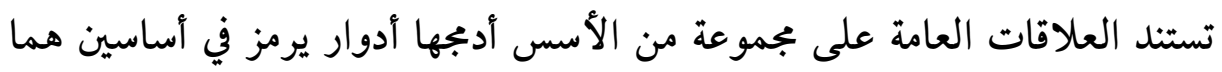

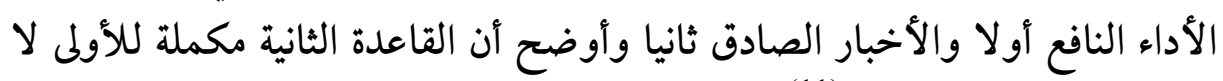

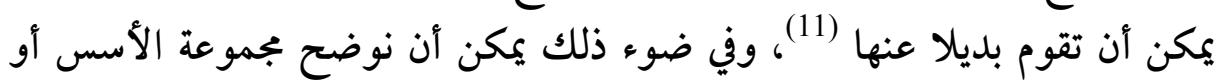
المبادئ التي تقوم عليها العلاقات العامة وهي:

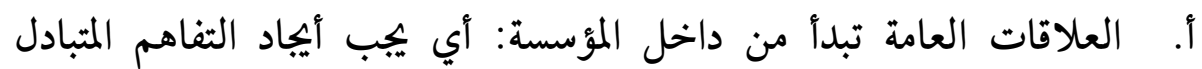

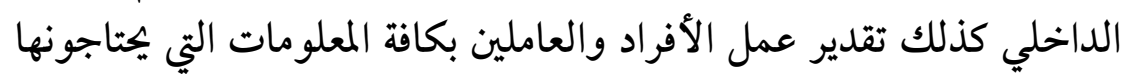

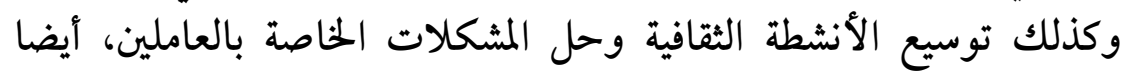

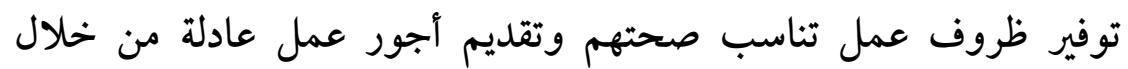

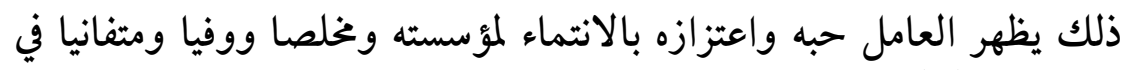
العمل فيها (12).

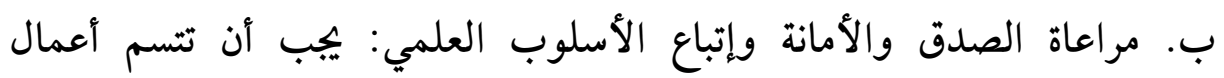

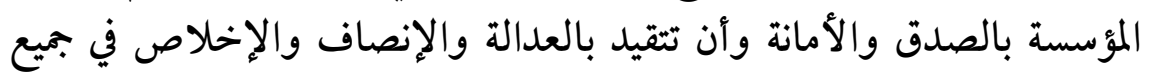

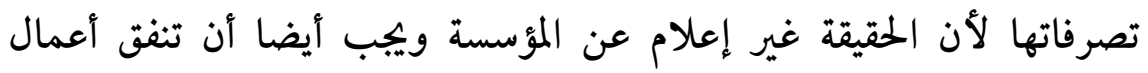

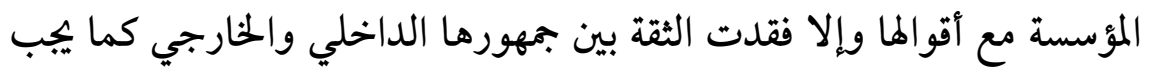

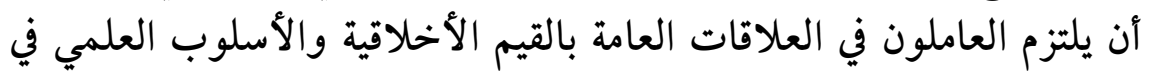
جميع تصرفاتهم الواقع أنهما مظهران متكاملان.

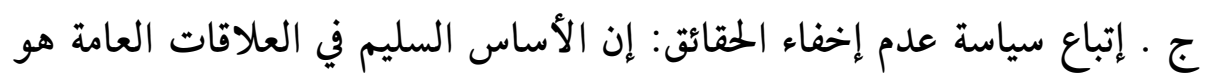

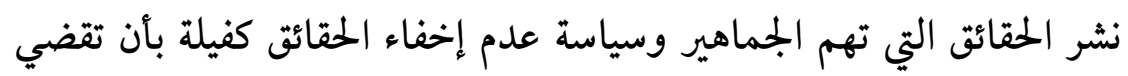

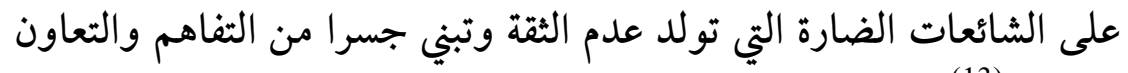
المثترك (13).

د. نشر الوعي بين الجماهير: يقع على عاتق العلاقات العامة شرح سياسة الدولة

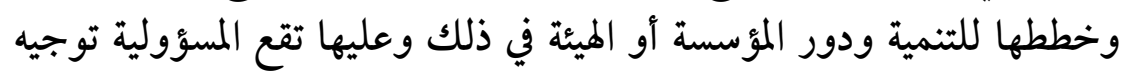
الرأي العام ودفع الجماهير على تأييد السياسة العامة لمؤسسات الدولي المولة المولية 
وتوظف المؤسسات الحكومية اختصاصين في العلاقات العامة لشرح أنشطتها

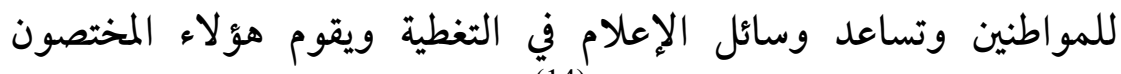
بتوصيل أراء الجمهور إلى المؤسسات (14)

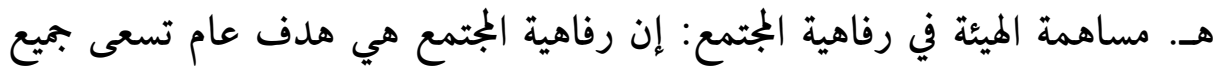

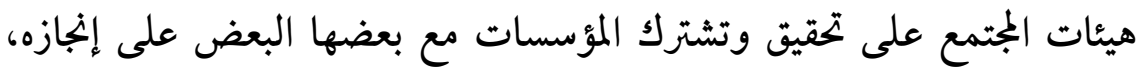

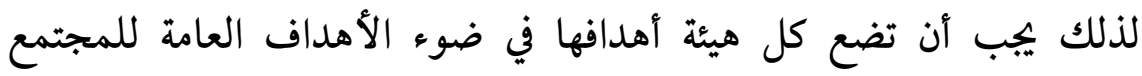

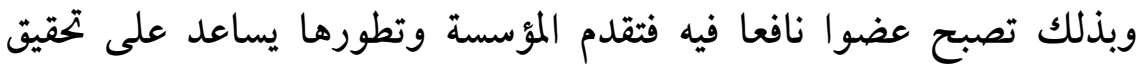

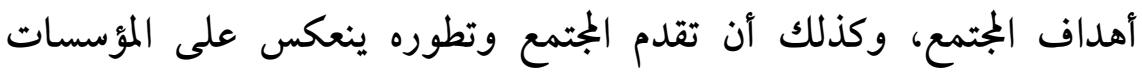

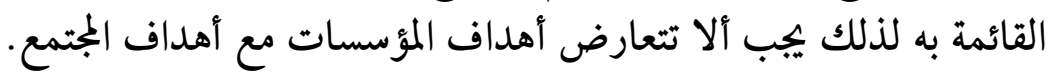
و.كسب ثقة الجماهير: تهلدف العلاقات العامة في أي منظمة من المنظمات إلى العمل

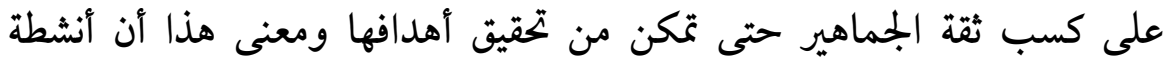

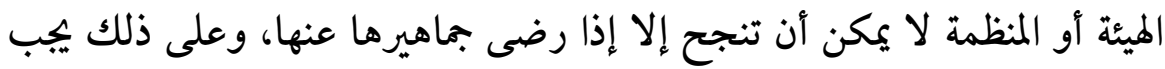

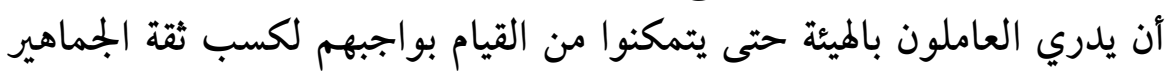

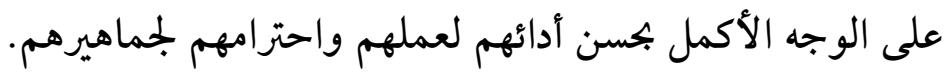

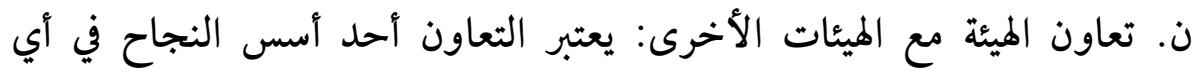

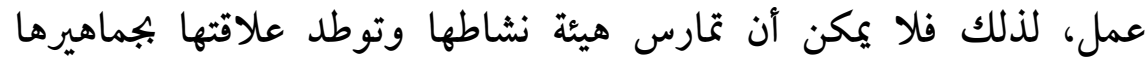

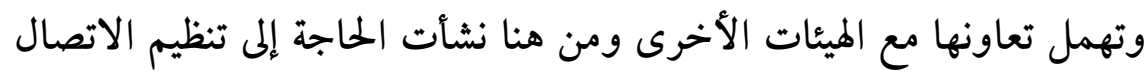

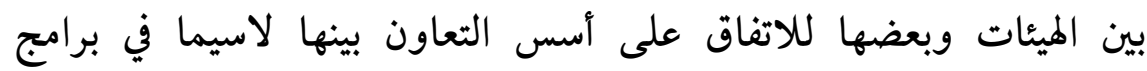

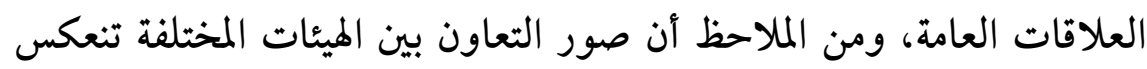

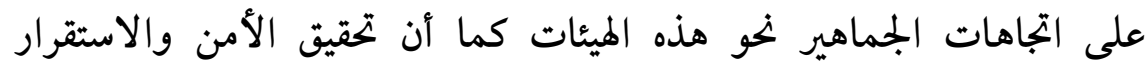

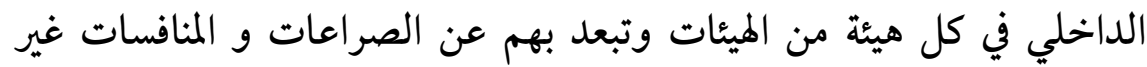

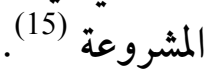




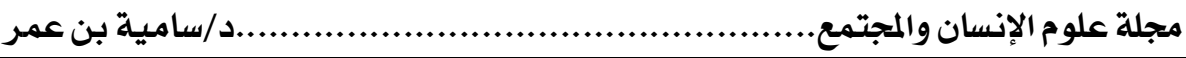

3

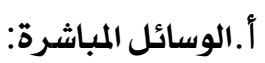

هي أكثر الوسائل فاعلية و تأثيرا في الجمههور لأن المرسل والمستقبل يكون

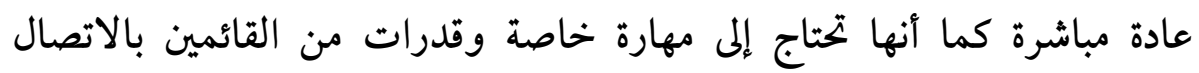

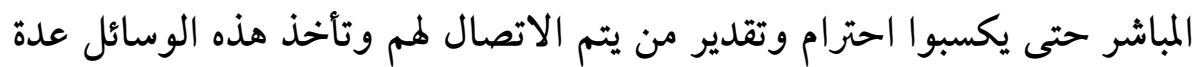

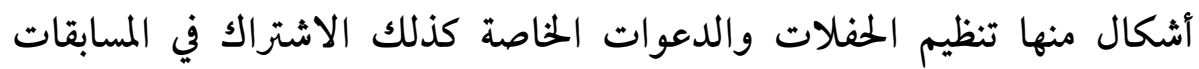

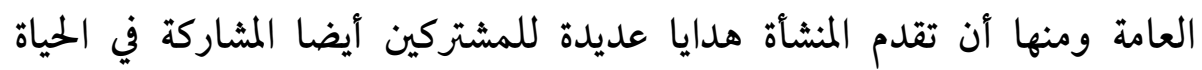

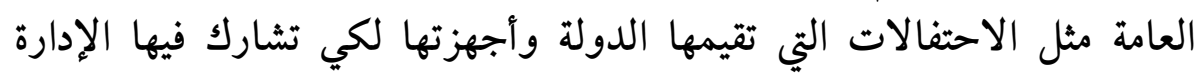

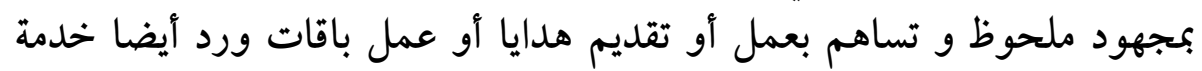
الجمتمع المحلي مثل إنشاء حضانة لأبناء الحي.

كذلك رعاية العاملين بالمنشأة ففيها تقدم الخدمات في الحالات العجز والإصابة وكذلك في الحالات الوفيات وغيرها من المواقف التي تستدعي وقوف

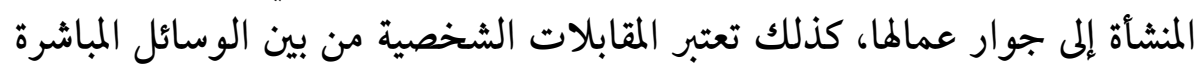

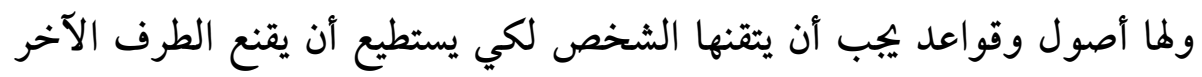

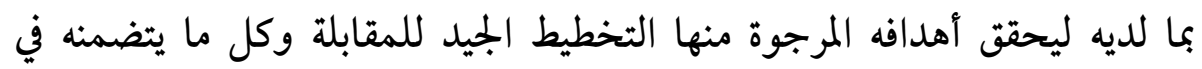

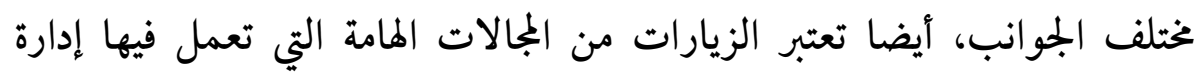

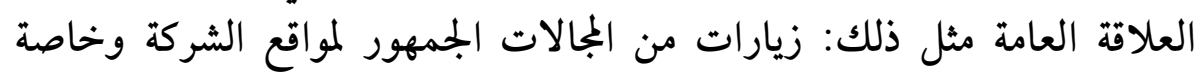

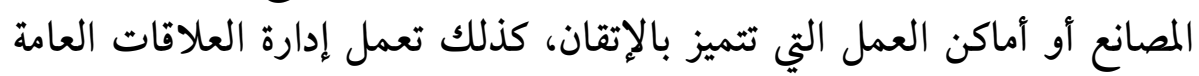

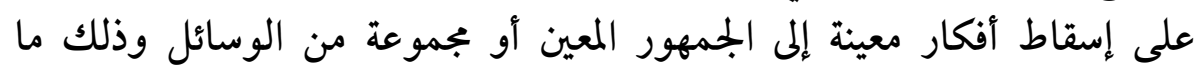

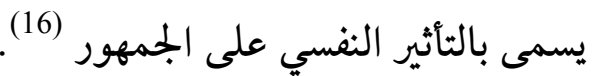

ب. الوسائل المقروءة و المكتوبة:

إن الإنتاج الفكري من خلال المكلمات لم يفقد |أهميته بل على العكس المك المكات ذلك تماما لقد أصبحت الكلمة المقروءة و المكتوبة المعبرة عن المجتمع والإنسان

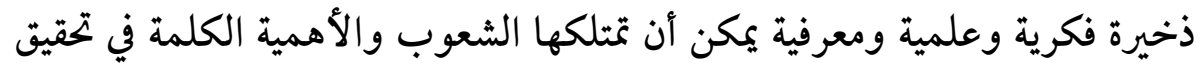


أهداف تكنولوجيا الاتصال والإعلام والثقافة الجماهيرية أصبح قياس تفوق

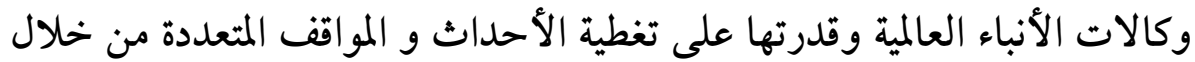
عدد ما يمكن أن ينتجه الفريق العلمي والبحث الثقافي والإعلامي في كل و وكالة

أيضا من بين الوسائل المجالات كذلك مطبوعات المنشأة ومنها النشرات

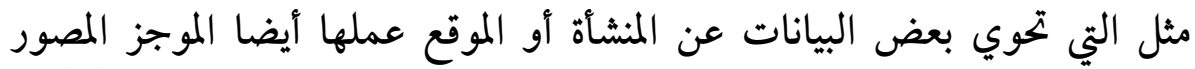

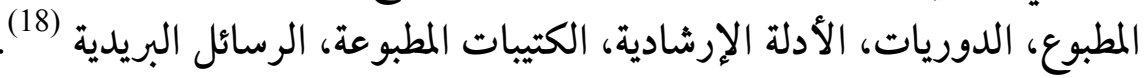
ج ـ الوسائل المسموعة:

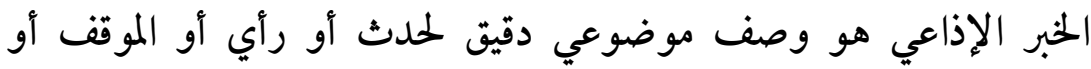

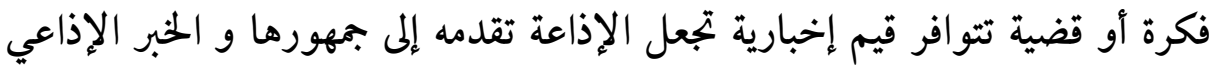

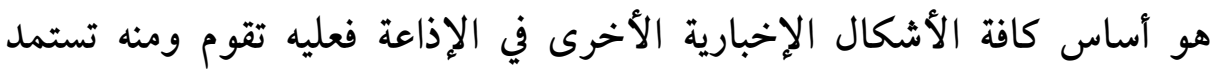

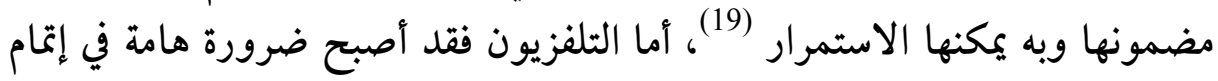

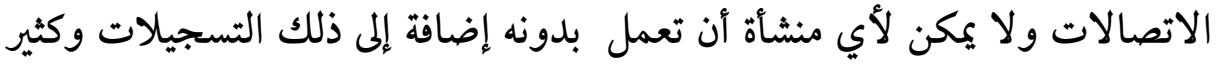

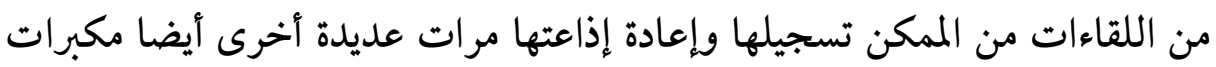

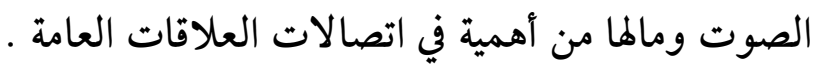

د. ـ الوسائل المرئية:

وهي التي تتمثل في الصوت والصورة معا و التي يمكن أن تظهر على شاشة

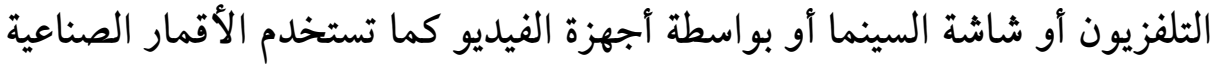

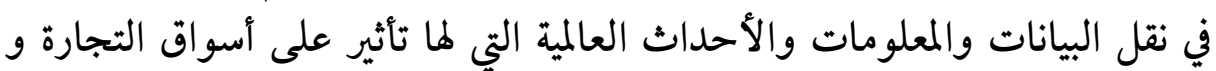

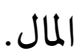
و. قنوات الاتصال الرديئة:

هناك قنوات للاتصال وإن كانت توصل بين طرفين إلا أنها لا تحقق علاقة واضحة وسليمة بل غالبا ما تكون كاذبة أو وهمية لا تمثل الحقيقة ومن هذئ وند

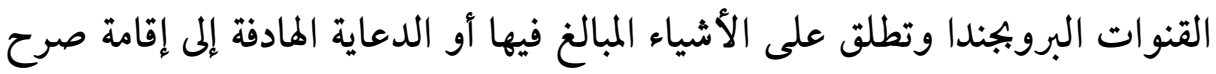


من الوهم و الخداع حول شخص معين أو حدث يهتم به الناس وعند اكتشافها

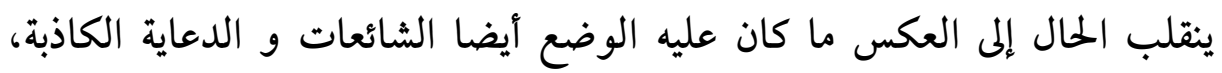

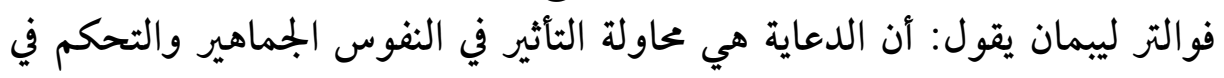

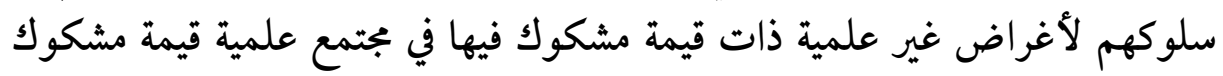
فيها في المجتمع ما وزمان معين. هـ. الاتصالات الداخلية و الخارجية :

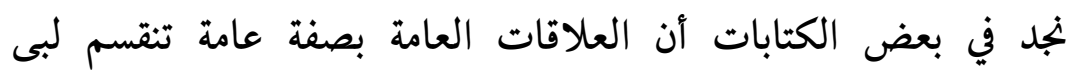

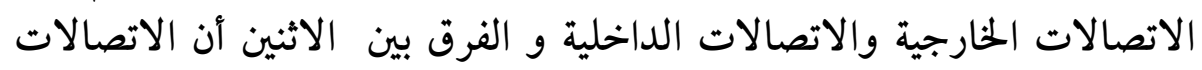

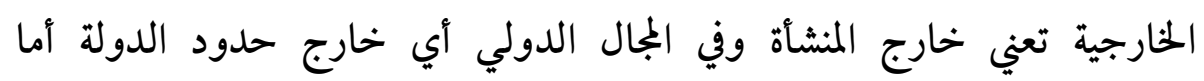

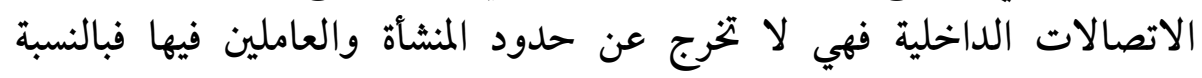

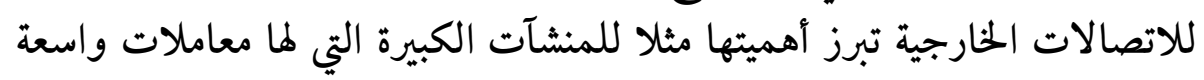

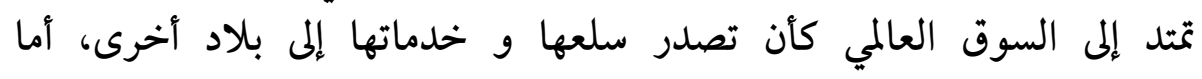

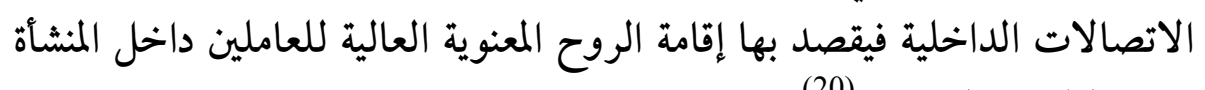
بشتى الطرق والوسائل (20). ن. الاتجاهات الحديثة في الاتصال و العلاقات العامة: ولاتجاهات الحديثة في مفهوم الاتصالات والعلاقات العامة أنهما يعملان

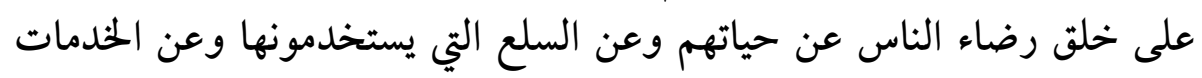

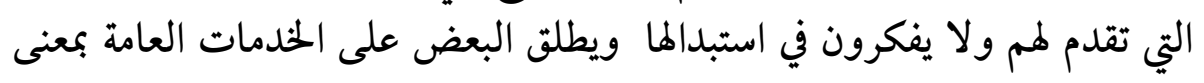

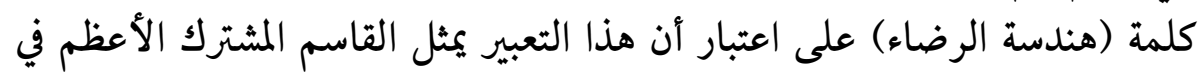

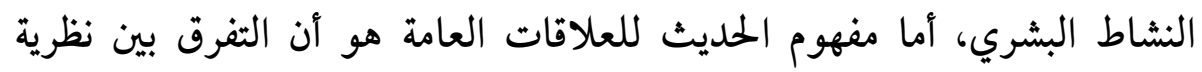

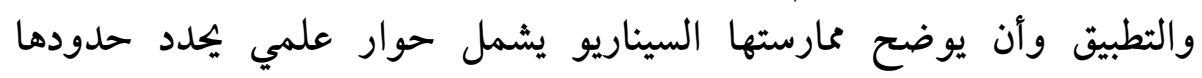

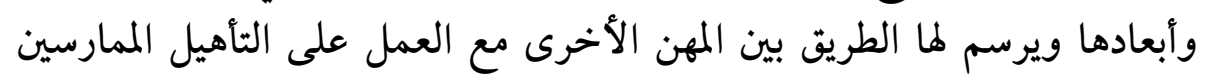

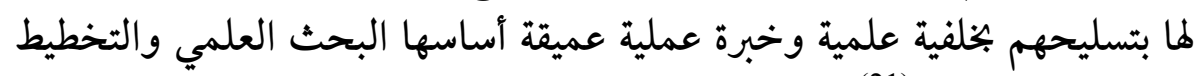
وقياس الرأي العام (21). 
4. خبراء العلاقات العامة:

أثبتت التجارب و الدراسات المختلفة أن نجاح جهد التطبيق في التحقيق

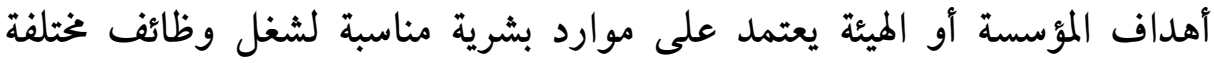

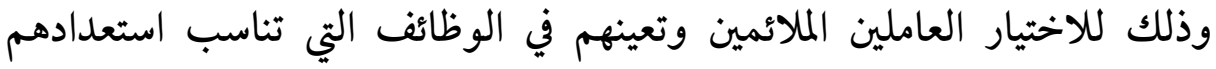

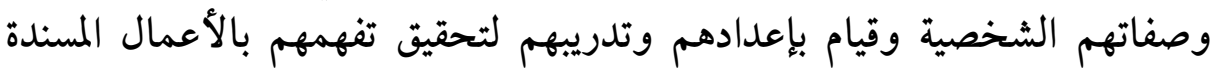

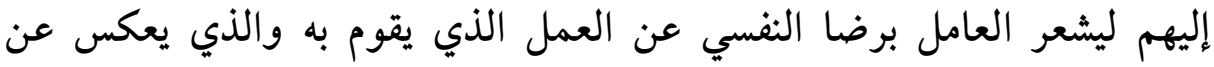

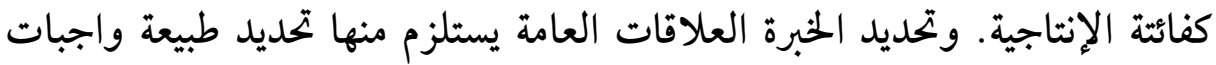
الوظيفة ومتطلبات هذه الوظيفة من الصفات و القدرات المختلفة.

أ. طبيعة واجبات وظيفة العلاقات العامة : إن المجال الوظيفي لحبير العلاقات العامة

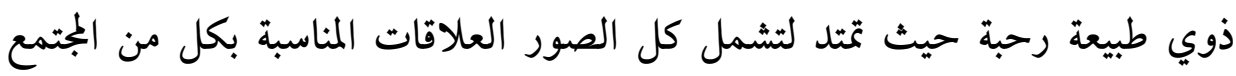

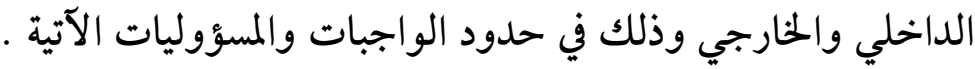

1.يعاون يسدي المشورة إلى إدارة المؤسسة أو الميئة في كل ما يتصل بها أو سياستها

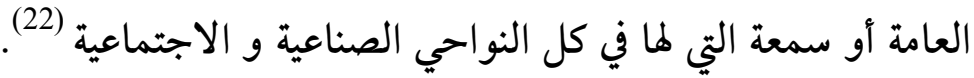
2.إحاطة الجمهور بالبيانات والمعلومات عن الشركة وحدود سياستها العامة ومعرفة مدى تجاوب مع اتجاهات الرأي العام. 3.انجاز عمليات النشر والإعلان في الصحف والمجلات المختلفة بالاشتراك مع دار المبار المبيعات ومتابعتها مع الميئات المختصة.

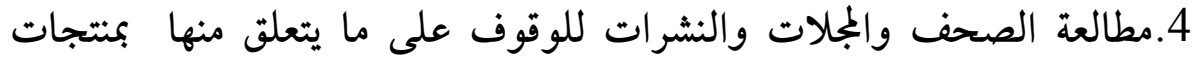

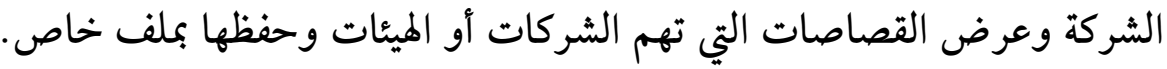
5.الاشتراك في تنظيم المعارض للتعريف بنشاط الشركة الإنتاجي. 6.تنظيم الزيارات للزائرين والخبراء الواردين إلى الشركة وحسن استقبالهم. 7.إعداد التقارير اللازمة والبيانات الخاصة بموقف الشركة من الإعلان والنشر

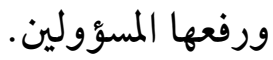


8.بعد مشروع ميزانية جهاز العلاقات العامة ويعرضه على رئيس إدارة المؤسسة

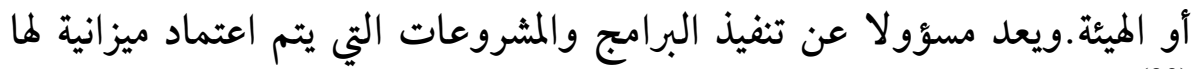

ب. المتطلبات الوظيفية في خبير العلاقات العامة: هناك بجموعة من المتطلبات التي يجب توافرها في خبير العلاقات العامة يمكن تقسيمها إلى: 1.خبرات تعليمية وثقافية:إن تحقيق الكفاءة الفنية في ميدان العلاقات العامة والدراسات

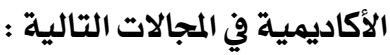

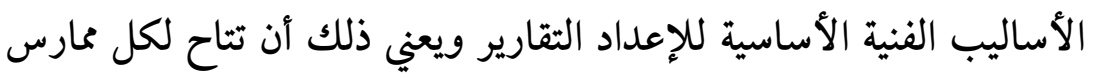

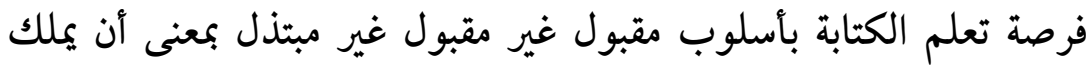

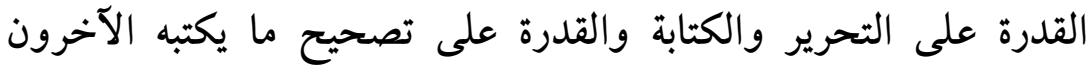
فضلا عن المقدرة في العمل التحريري تحت إشراف الآخرين.

تهتم بعض المنشآت باختيار أخصائي العلاقات العامة من ذوي المهارة

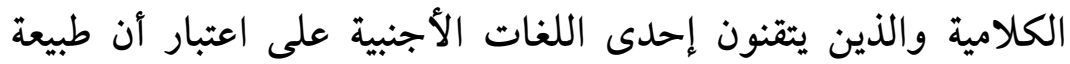

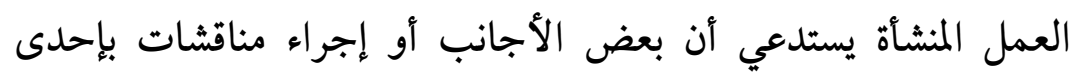

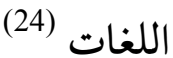

الاهتمام بدراسة العلوم الإنسانية :الاجتماع وعلم النفس والاقتصاد والعلوم السياسية مثل هذه المعلومات تهياً خليفة أساسية في السلوك تلان الإناه

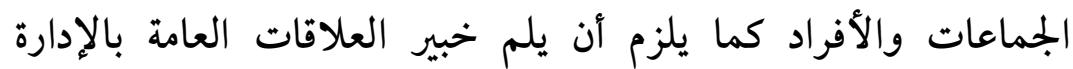
والتحليل المالي والعلاقات الحكومية مع مؤسسات الأعمال. التدريب على عمليات قياس تحليل الرأي العام والإحصاءات الأساسية

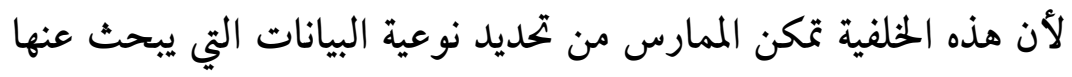

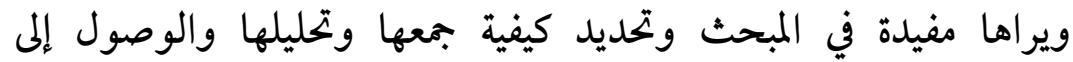
النتائج و تطبيقها فيدة في (25). 
2.الصفات الشخصية:هناك بجموعة من الصفات الشخصية التي يجب أن يتصف بهات المهات

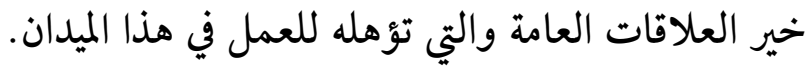

حسن المظهر: لعل حسن المظهر من الأشياء الهامة في عمل أخصائي أو أخصائية

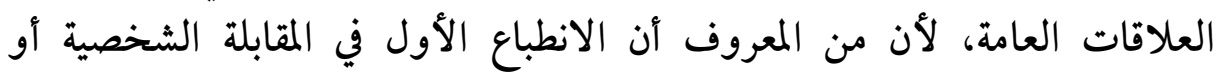

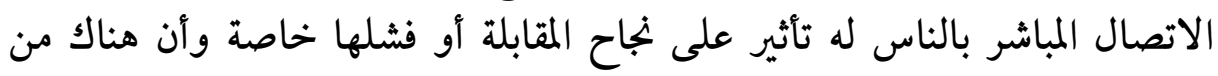

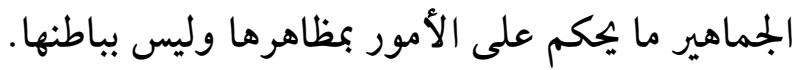

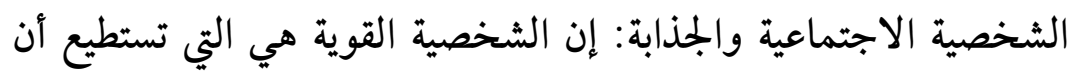

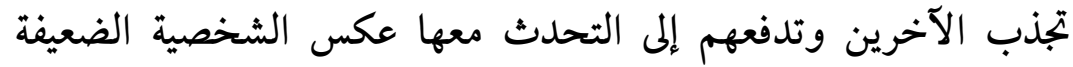
التي لا تلفت الأنظار (26).

كما لابد أن يملك خبير العلاقات العامة بصفة القدرة على الثفكير

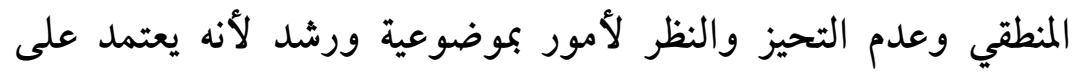

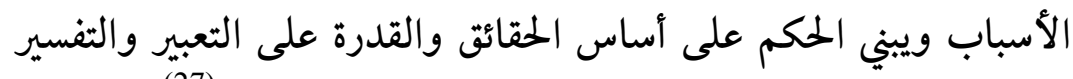
بالاختيار والقدرة على الغلق والإبداع في الكتابة و الخطابة (27).

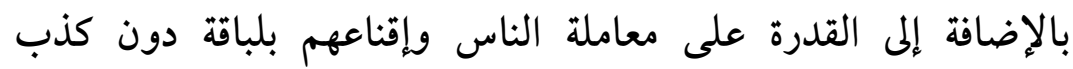

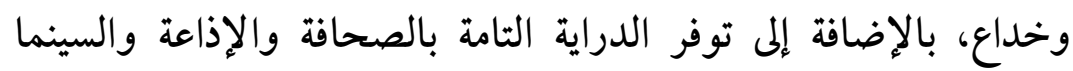

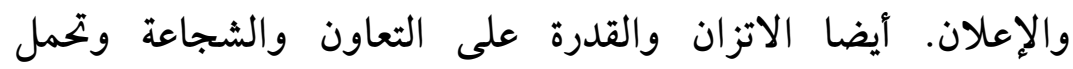

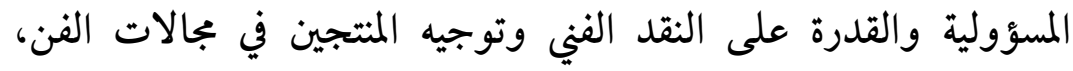
الرسم وعمل الملصقات وإقامة المعارض وغئ وتيرها من الدراية الثامنة بفنون

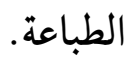

• القدرة على تكوين علاقة طيبة بالرؤساء والقادة والمسؤولين ونقابات

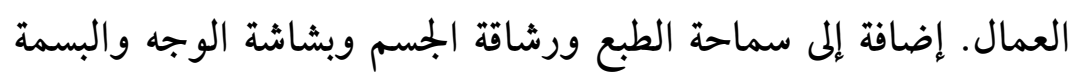

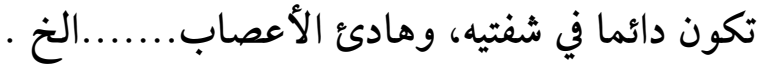




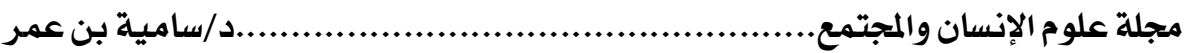

5. المد خل السوسيولوجي و دراسة العلاقات العامة :

إن الدراسة المتعمقة للعلاقات العامة لابد وأن تبدأ من نقطة انطلاق محددة فما من علم ينشأ في فراغ نظري أو منهجي، ومن هنا كانت الاستعانة

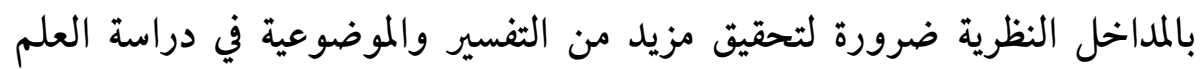

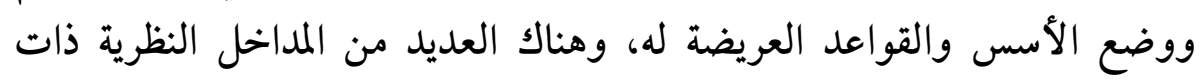

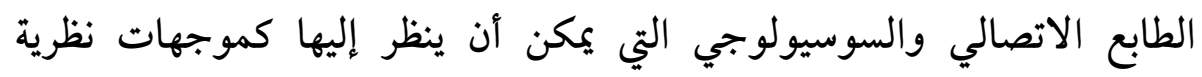

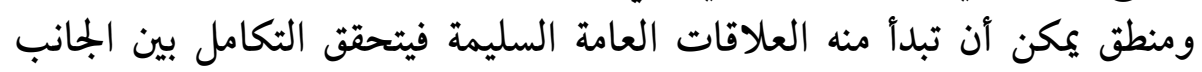
العلمي والتطبيقي.

لذا سنتطرق الم المدخل السوسيولوجي من خلال بعض اتجاهاته النظرية الهادفة إلى شرح وتوضيح وضبط كل ما يتعلق بالعلاقات العامة كعملية إضافة إلى

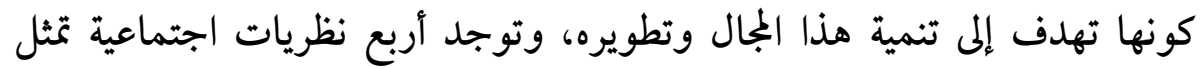

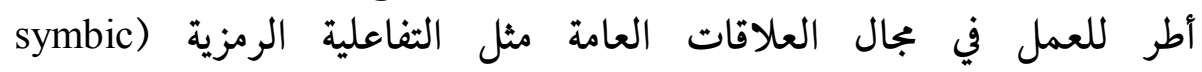

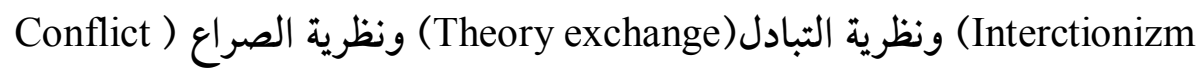

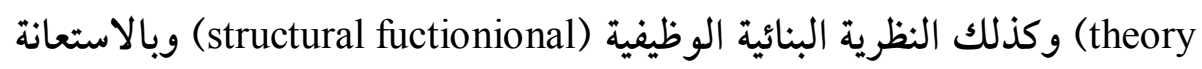

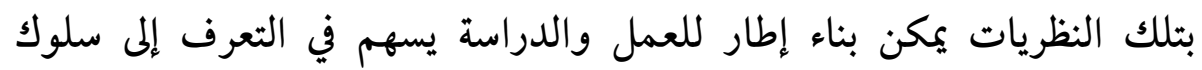

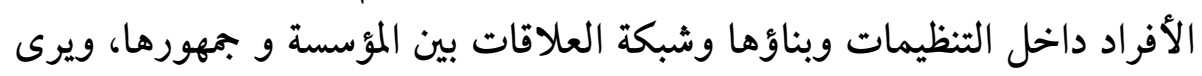

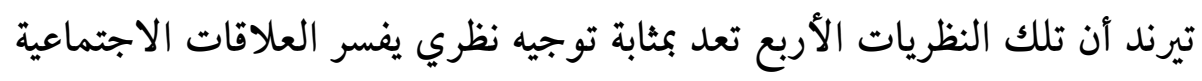

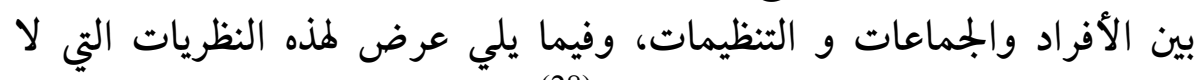
يمكن تجاهلها عند دراسة العلاقات العامة (28).

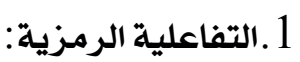

تمتد جذورها إلى المدرسة السلوكية وتفترض التفاعلية الرمزية أن الواقع

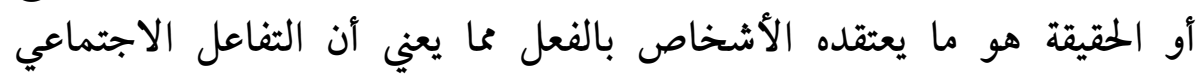

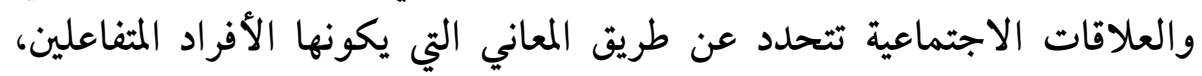

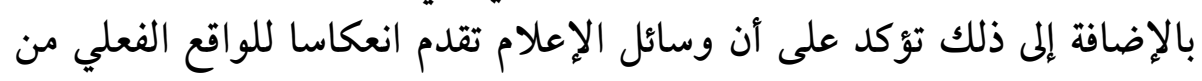

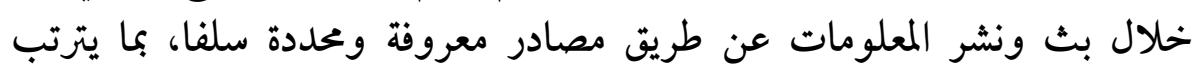




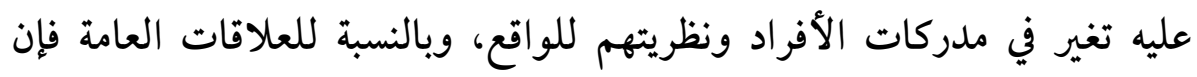

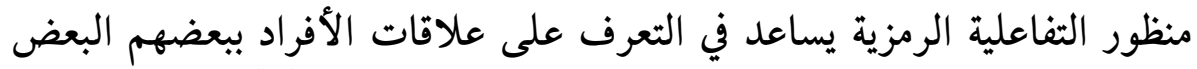
وعلاقتهم بإدارة العلاقات العامة وبالتنظيم الذين ينتمون إليه (29) كما لخص "بلومر" القضايا الأساسية للتفاعلية الرمزية في ثلاث مقدمات

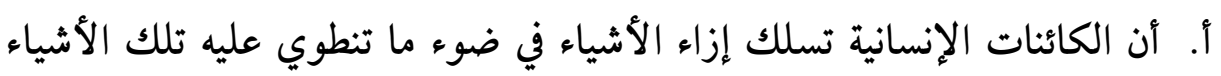

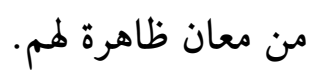
ب. أن تلك المعاني هي نتاج للتفاعل في المجتمع الإنساني. أن هذه المعاني تتعدل وتتشكل خلال عملية التأويل الذي يستخدمها كل فرد في تعامله مع الرموز التي تواجهه (30).

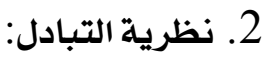

يشير مفهوم التبادل الاجتماعي إلى تلك العملية التي يتم من خلالها تبادل

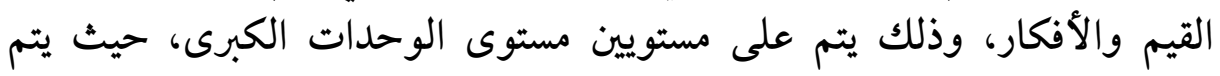

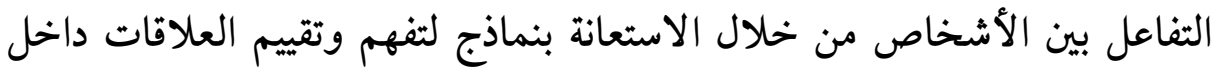

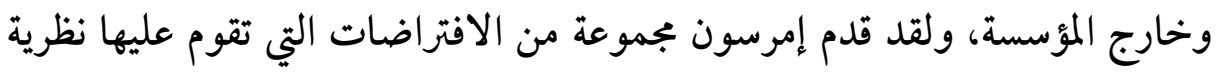
التبادل وتتخلص في ثلاث عناصر أساسية: أ.أنم الأفراد يسلكون بالطريقة الذي يجقق لهم النفع والفائدة.

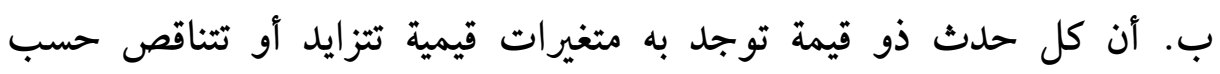
الحاجة التي ينطوي عليها ذلك الحدث. ج. أن المنفعة أو الاستفادة من التفاعل الاجتماعي تكون مشروطة بما يتحقق من نفع خلال عملية التبادل.

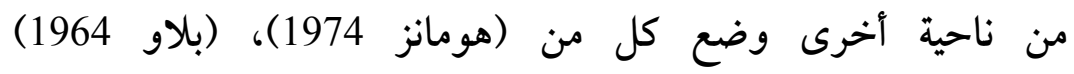

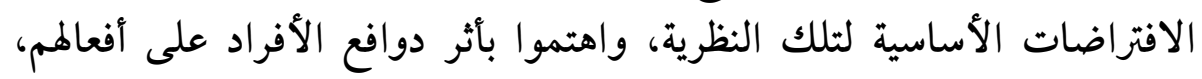

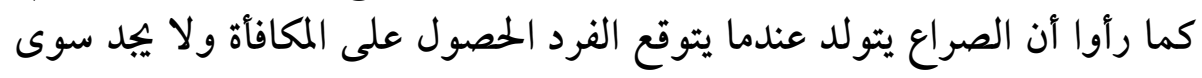


العقاب، أما إذا ركز أخصائي العلاقات العامة على المؤسسة كوحدة للتحليل

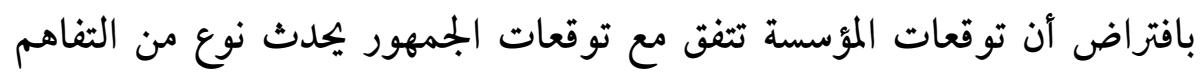

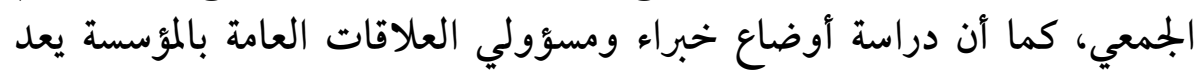

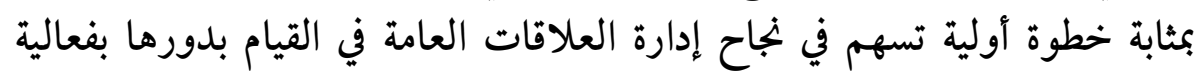

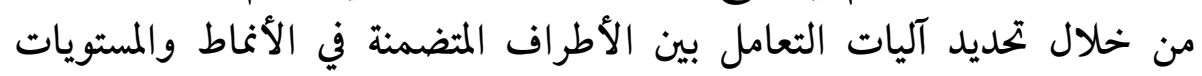

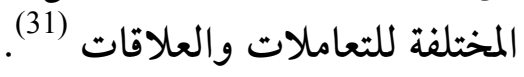

3. نظرية الصراع:

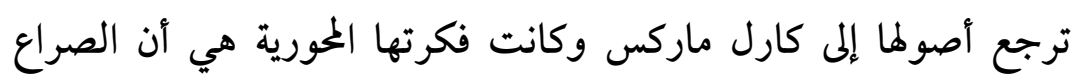

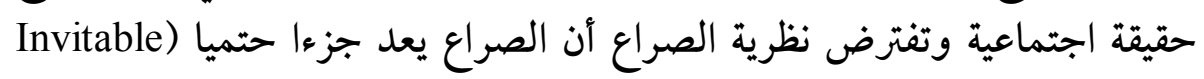

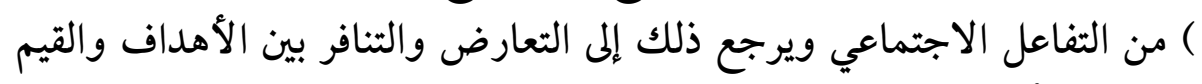

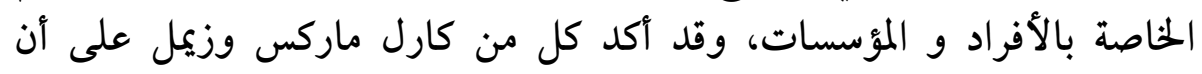

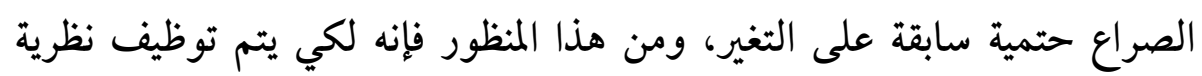

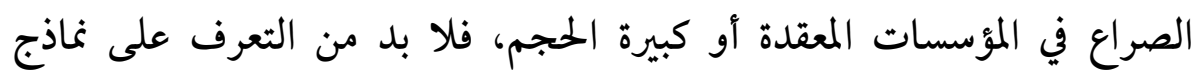

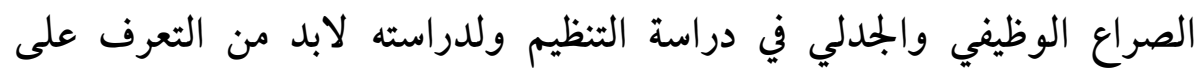

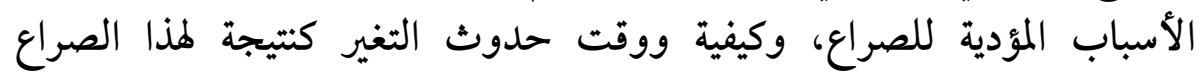

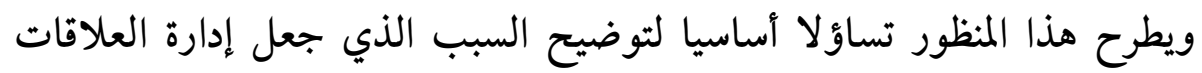

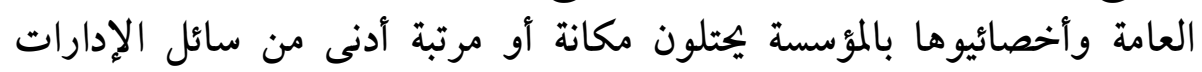

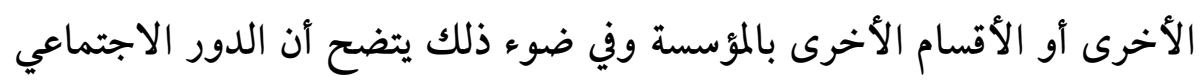

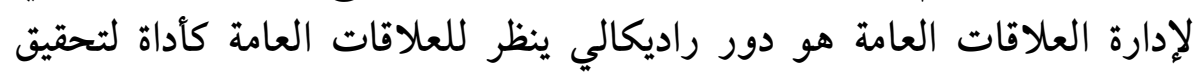

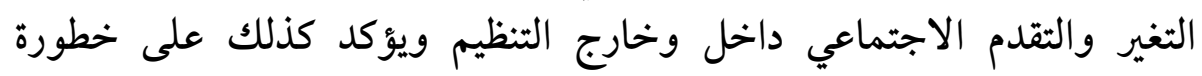
وأهمية الاتصال الثنظيمي كما ينظر للعلاقات العامة كأداة لإدارة الصراع.

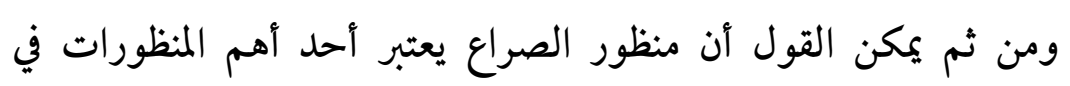

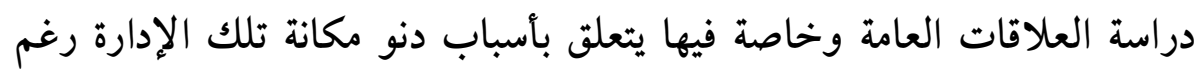

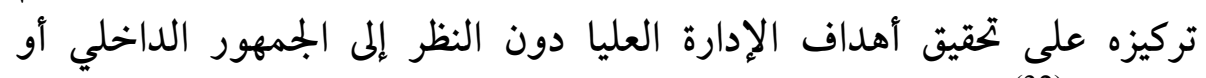

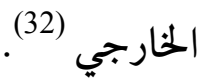


4. النظرية البنائية الوظيفية:

تنظر إلى المؤسسة باعتبارها شبكة العلاقات الاجتماعية بحيث أن استمرار

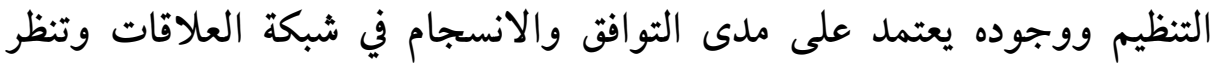

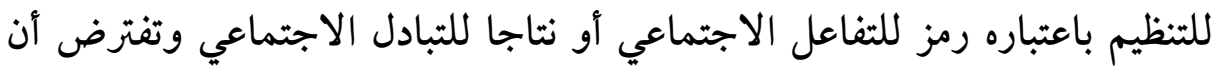

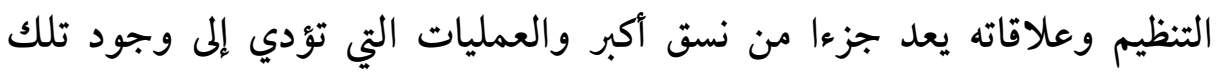

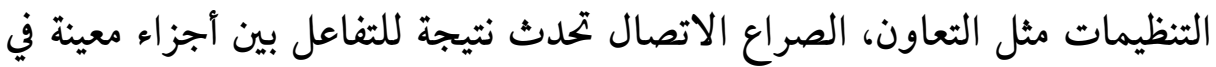

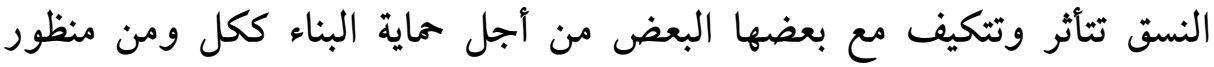

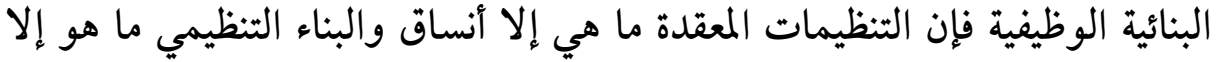

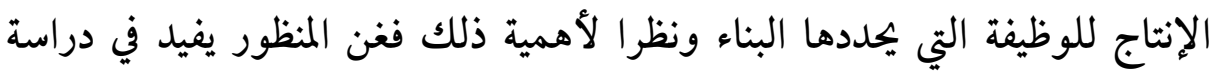

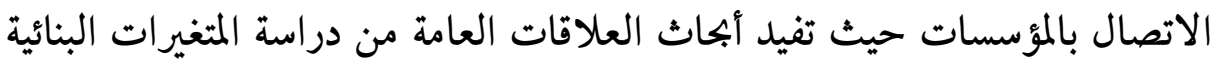
للتنظيمات ودور العلاقات العامة في البناء التنظيمي للمؤسسة. وييد الباحثين في ميدان العلاقات العامة حاجة لدراسة العلاقات العامة

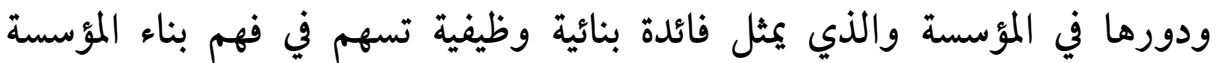

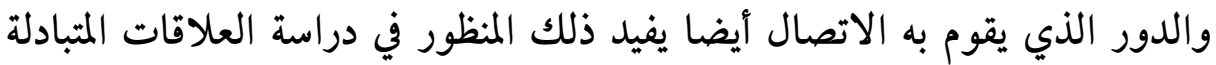

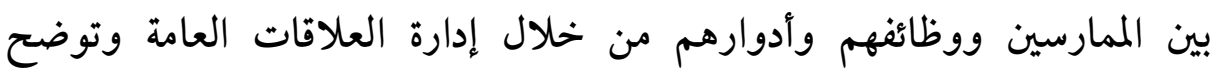

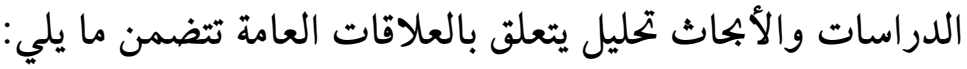
أ. تحديد مكانة ممارسي العلاقات العامة بالمؤسسة.

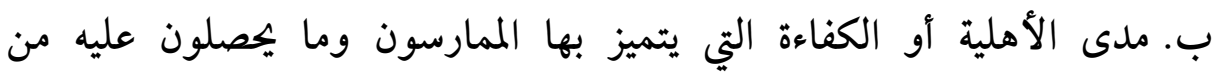
مكافآت.

ت.طبيعة الوظائف التي توكل إلى الإدارة وممارسي العلاقات العامة ومدى التهات إسهامها في تحقيق الأهداف الكلية للبناء التنظيمي المتمثل في المؤسسة (33)

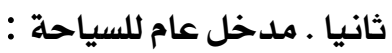

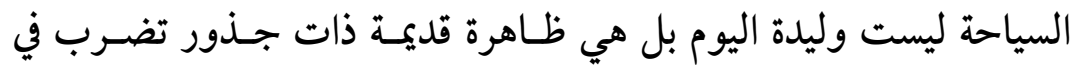

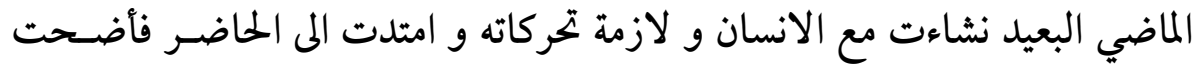


حركة واسعة تتطور مع سائر التطورات التي تحدث داخل المجتمع ، ولكـن مـا هـي

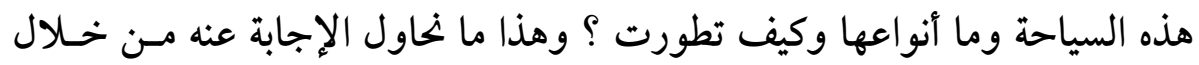
العناصر التالية : مده التساحة

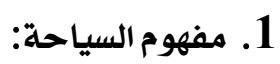

لقد تطور مفهوم السياحة و معناها مع الثقدم الحضري الذي يجيى في ظله

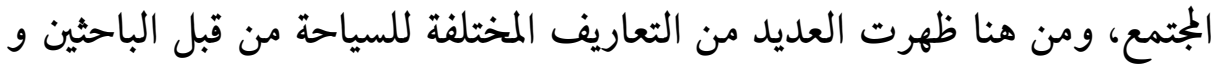

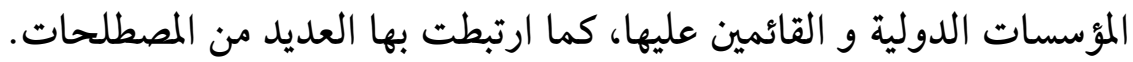
و ظهور علم السياحة كعلم جديد ميز للقرن العشرين في النصف الثاني منه

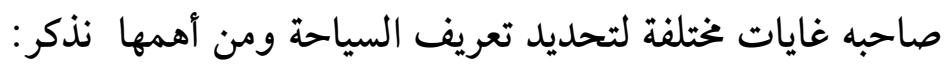
- غاية إحصائية: كاحصاءات السياح و عدد الزيارات. - غاية قانونية: و ذلك للوصول المى قواعد واضحة للنشاط السياحي. - غاية علمية: من المهم تحديد ماهية السياحة و تنضيم إشكالها لكي تتسنى دراستها. - غاية نظرية: و هي عبارة عن بجموعة المعارف المتعلقة بالنشاط السياحي عامة

و من بين ابرز تعاريف السياحة نذكر مايلي:

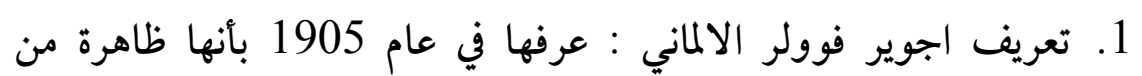

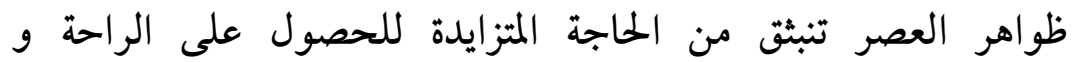

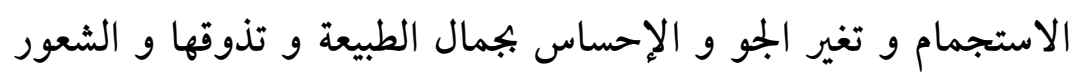
بالبهجة و المتعة في الإقامة ذات طبيعة خاصة الإحس (35).

2. تعريف هيرمان فون النمساوي: عرفها سنة 1910 على أنها اصطلاح

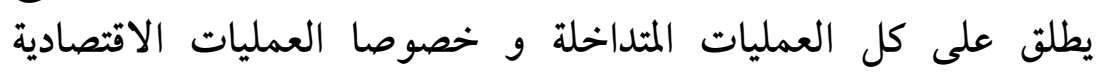


المتعلقة بدخول الأجانب و إقامتهم المؤقتة و انتشارهم داخل منطقة ما أو خارجها أو دولة معينة (36).

3. تعريف حمدي عبد العظيم: هي مجموعة النشاطات المختلفة التي تخدم المبام

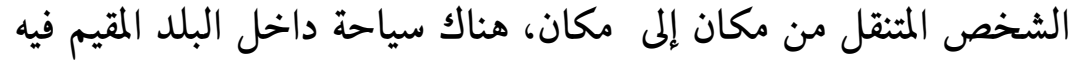

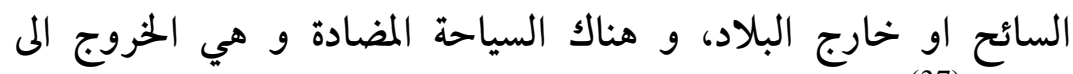
الخارج (37)

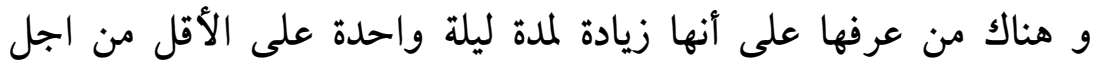

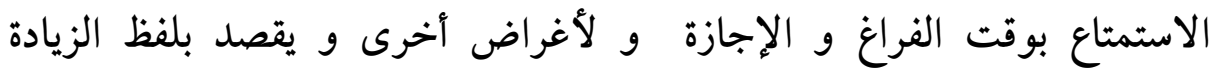

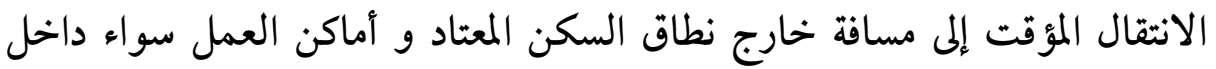

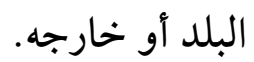

1. والبعض يرى بأن السياحة النشاط الحضاري و الاقتصادي تنظيمي

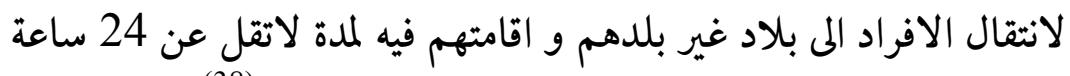
لأي غرض ما عد العمل الذي أجراه داخل البلاد الماد المزار (38).

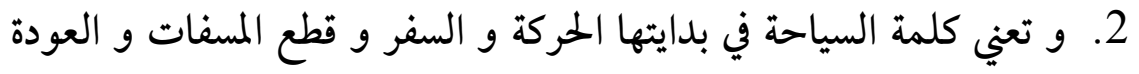

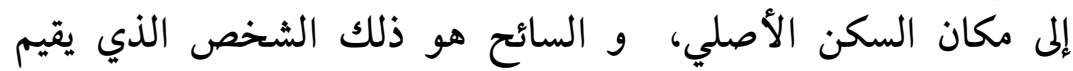

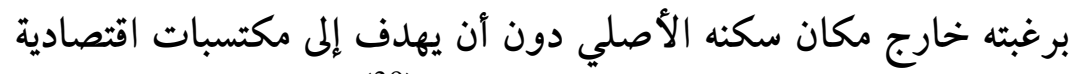
و عليه ان يصرف أموالا وفرها في مكان أخر (39).

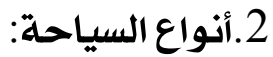

تتميز الساحة بكثرة أنواعها و أشكالها و يككن تقسيمها بشكل عام إلى

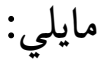

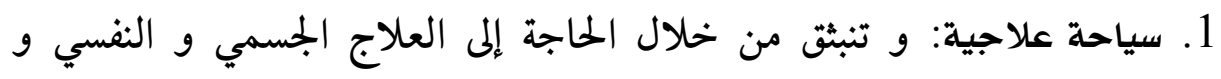

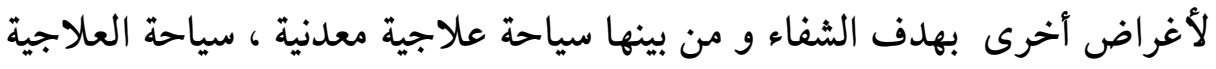
بحرية، سياحة علاجية مناخية. 
2.سياحة دينية: و تتمثل في زيارة المواقع الدينية في العالم مثل موسم الحج و

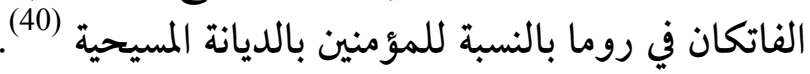

3.السياحة الرسمية: و تنقسم المى سياحة اقتصادية من خلا المعارض التجارية و

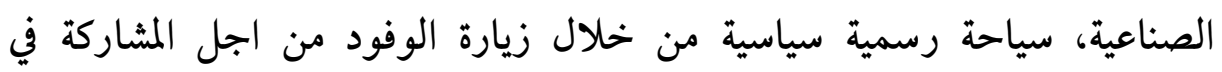
اللقاءات السياسية او احتفالات دولية معينة .

4.السياحة الرياضية: تتمثل في السفر و الإقامة للمشاركة الفعلية في المباريات

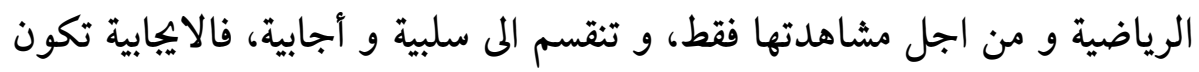

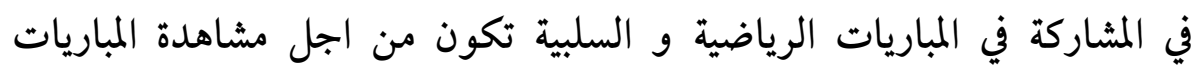
الاحتفالات الرياضية (41).

5. السياحة الثقافية: تهدف الم زيادة المعرفة و الغرض منها دراسة عادات الشعوب و تقاليدها.

6. السياحة الرقمية: تكون مـن اجـل المتعـة و الاسـتجمام تكمـن فيهـا الحاجـة الى الى الراحة

7.السياحة الاجتماعية: تكون لأجل زيارة الأقارب و هي معروفة في الدول التي لها جاليات في دول بجاورة (42). 3.نشأة السياحة:

بعد التطرق المى مفهوم السياحة و أنواعها يمكن التطرق المى أهم المراحل التي مر بها هذا المفهوم وكان ذلك كمايلي:

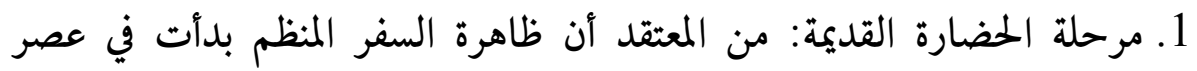

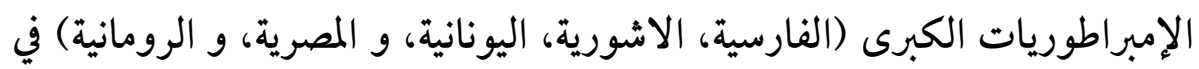

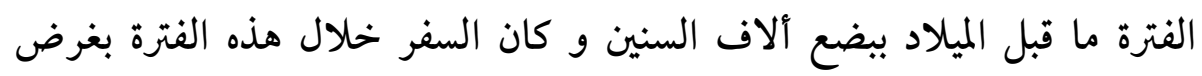

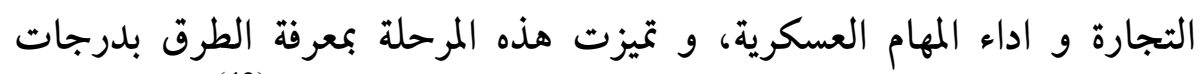

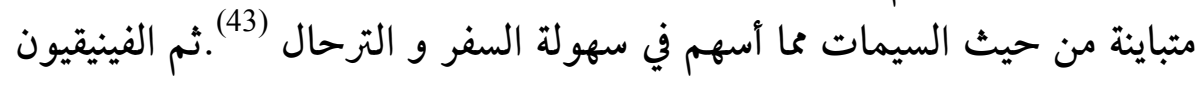




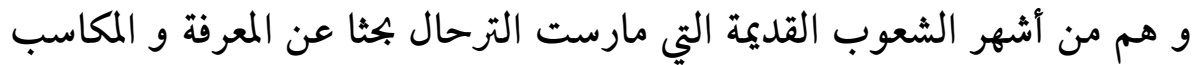

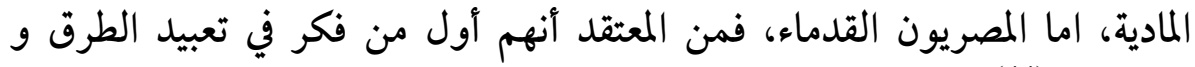

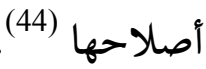

2.مرحلة العصور الوسطى: استغرقت الفترة الممتدة بين حوالي القرن الخامس و المّاس

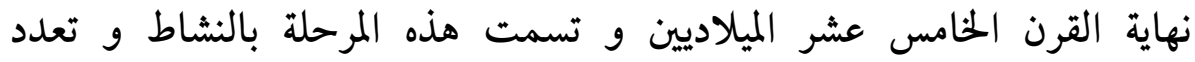

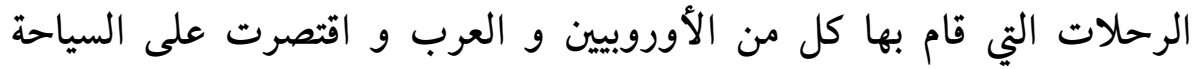

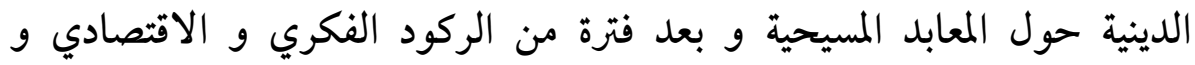

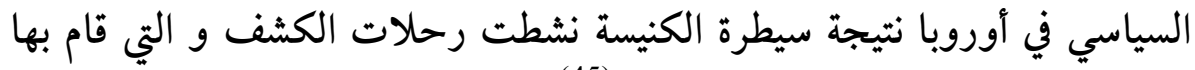
عدد من الرحالة داخل أوربا و خارجها (45).

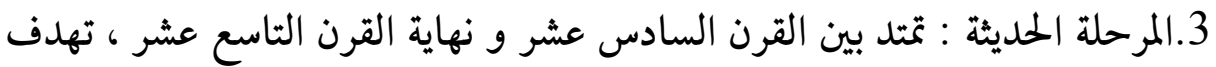
إلى تكثيف الرحلات الكشفية الأوربية صوب الأجزاء الداخلية من قارة إفريقيا و

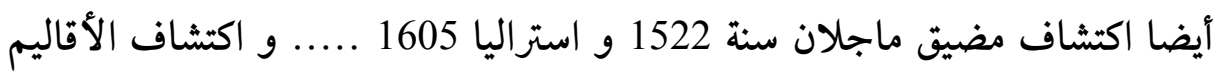

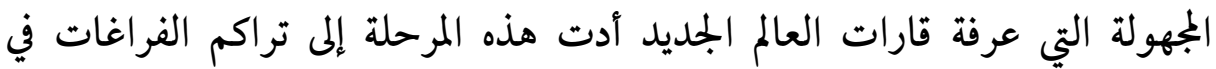

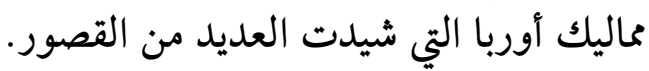

4.المرحلة المعاصرة : تمتد من نهاية القرن تسعة عشر المى يومنا هذا و يطلق عليها

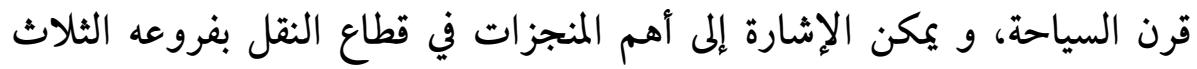

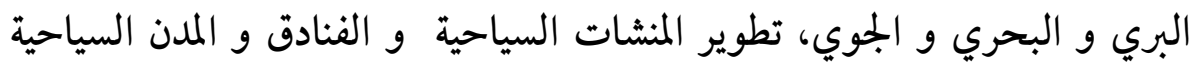

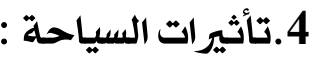

يظهر تأثير السياحة في الجوانب الثقافية من خلال نمطين من المجتمعات،

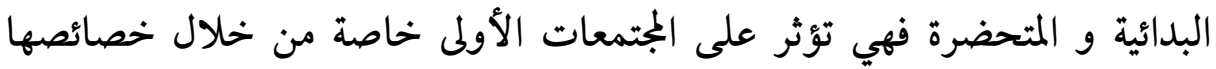

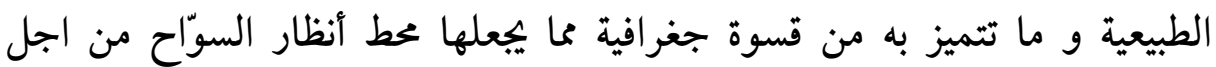

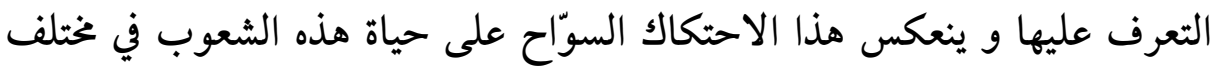

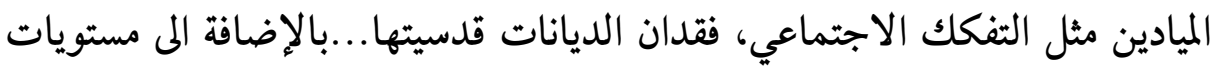




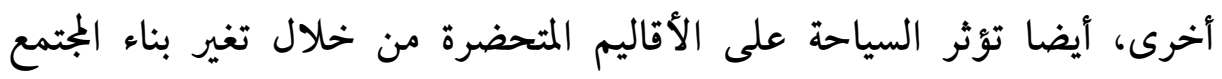

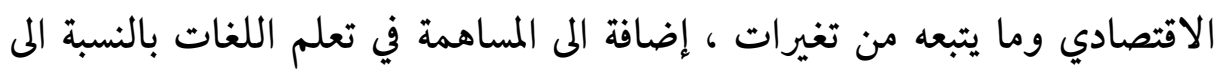

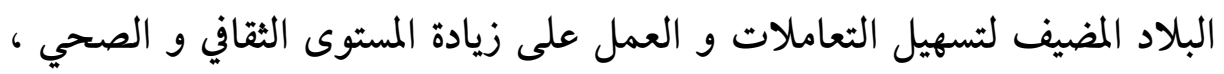

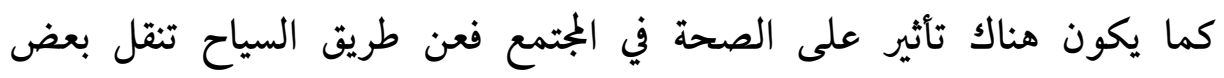

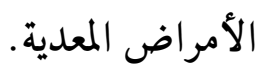

و تؤثر السياحة كذلك على السلوك الاجتماعي من خلال ارتباط السائح

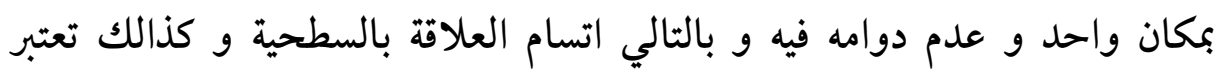

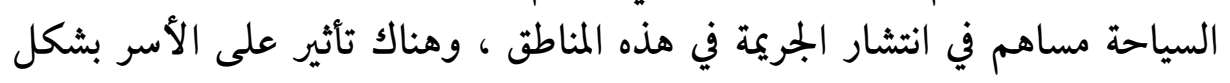

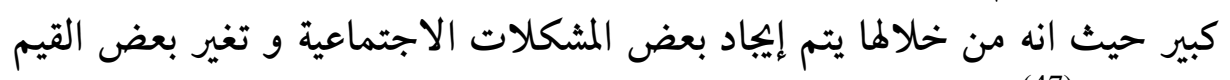
في المجتمع (47)، كبعض العن خادات والتقاليد الخاصة باللباس أو الأكل .....الخ. ثالثا: وظيفة العلاقات العامة في الميدان السياحي: 1 . تعريف العلاقات العامة السياحية:

تعرّف العلاقات العامة السياحية بأنّاتعبارة عن حلقة إتّصال لتوجيه

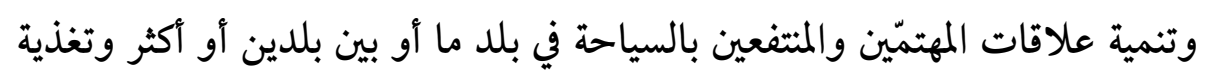

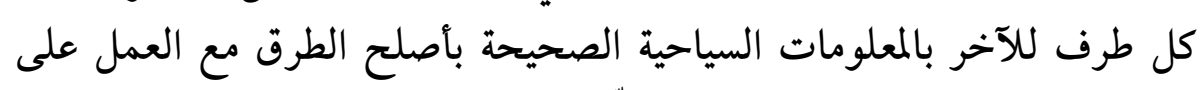

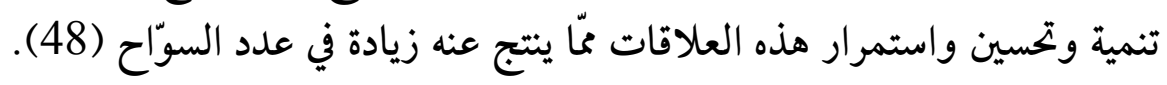

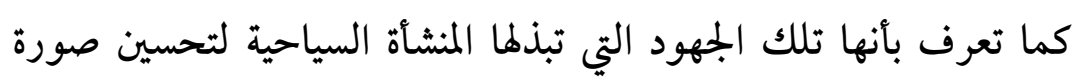

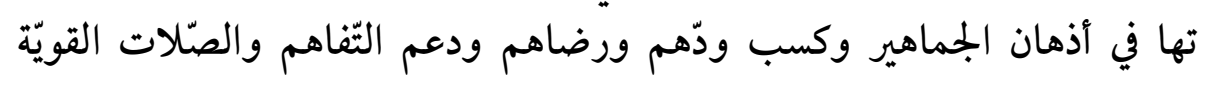

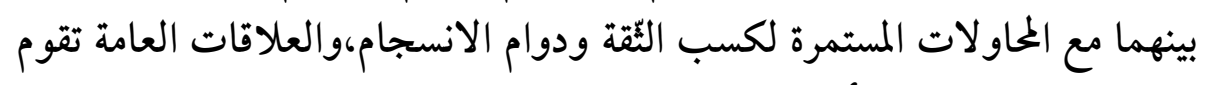

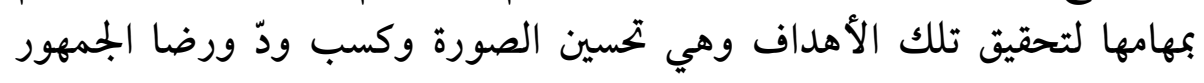

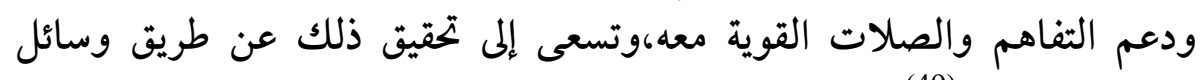
الترويج المختلفة (49).

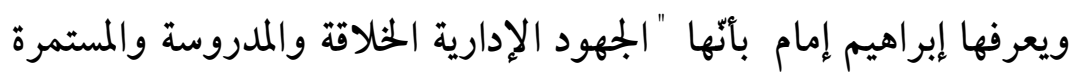

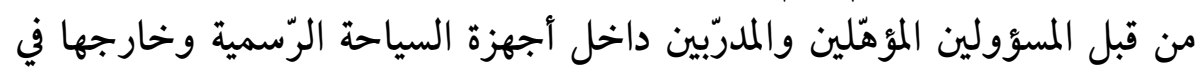


المؤسسات والشركات السياحية لنشر الحقائق والمعلومات والأفكار والآراء المتعلقة بالسياحة بما يساعد على إقامة جسور الصداقة والتّفاهم والثقة مع أبناء البلدان الأخرى لتحسين الصورة الذهنية عن بلد ما لتحقيق زيادة كبيرة في عدد السائحين

ومن خلال هذه التعاريف يمكن ان نقدم مفهـوم إجرائي للعلاقـات العامـة

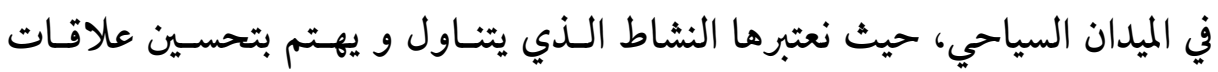

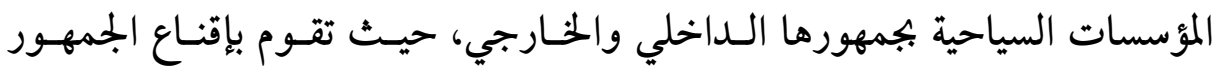

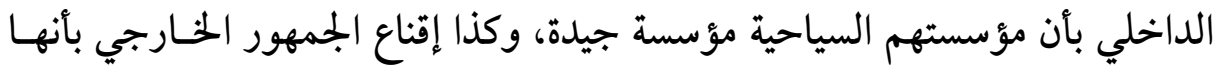

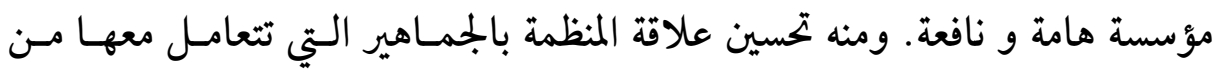

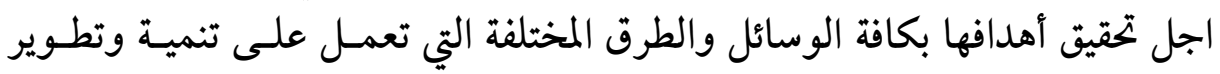
المؤسسة السياحية.

وعلى هذا فالعلاقات العامة ليست وظيفة إدارية يكلّف بها شخص أو قسـم

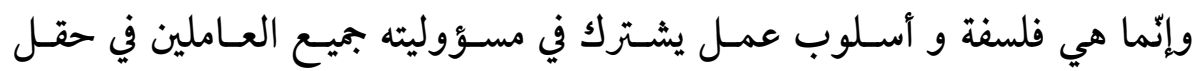

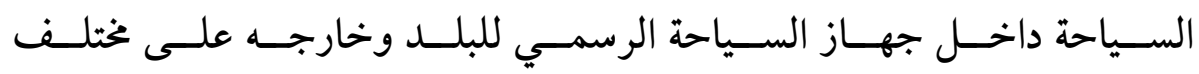
المستويات،لتحقق تكامل الصورة التي تظهر عليها السياحة لدى الجماهيه الريه.

2 ـ وظيفة العلاقات العامة داخل المنشآت السياحية:

تنحصر الوظائف الأساسية للعلاقات العامة بالمنشآت السياحية في

الوظائف التالية (51).

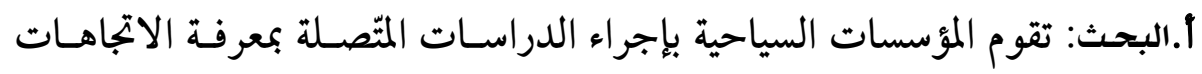

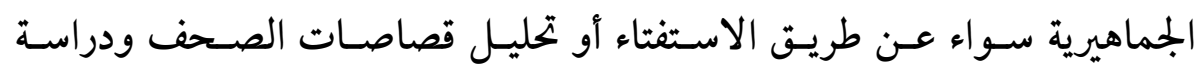

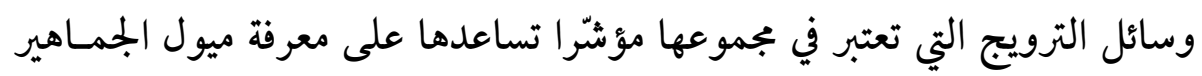

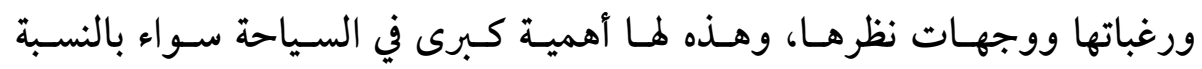

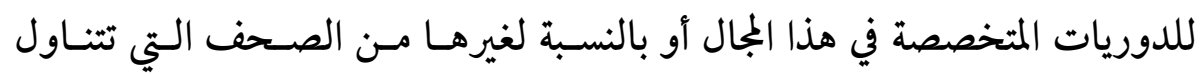

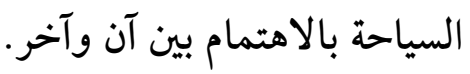


ب. التخطيط: يأتي بعد البحث وبعد أن تعرف رغبات السائحين ووجهات النّظر

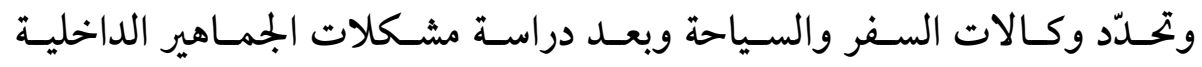

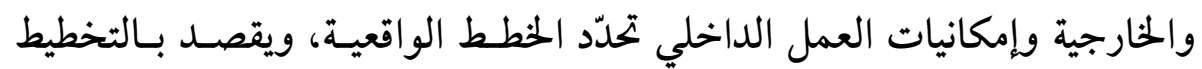

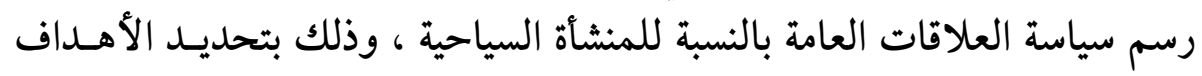

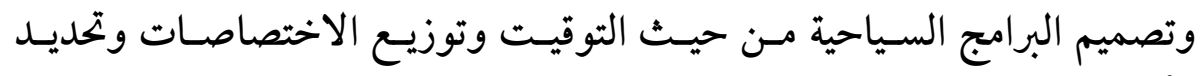
الأعمال وفقا للميزانية تحديدا دقيقا.

جـ. التنسيق: هو عمل أساسي يهدف إلى توحيد وجهات النّر عن طريست تجميـع

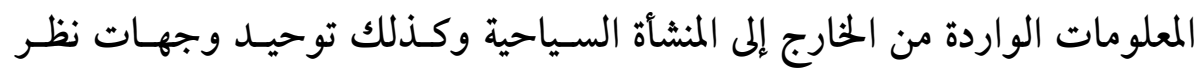

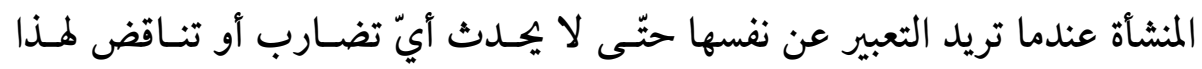

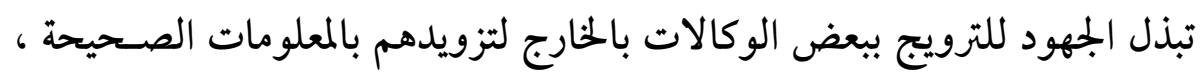

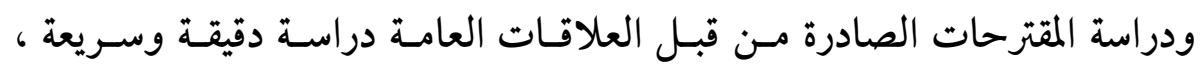

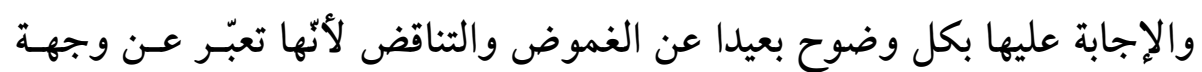

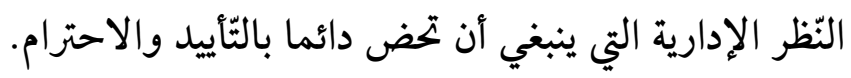

د. الإدارة: و تعني تقديم الخدمات لسائر الإدارات ومسـاعدتها على أداء وظائفها

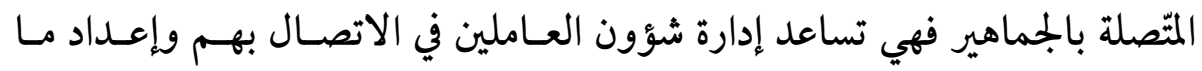

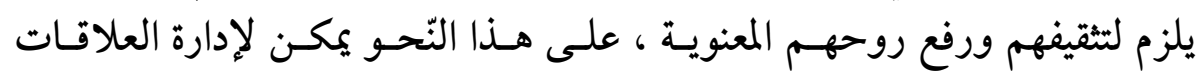

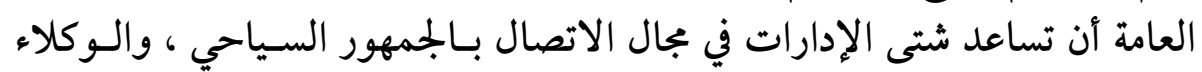

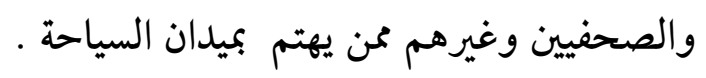
هـ.الإنتاج: وهذه الوظيفة تتصل بعدد كبير مـن الأعمـال المامـة المتعلّقــة بـالإعلام

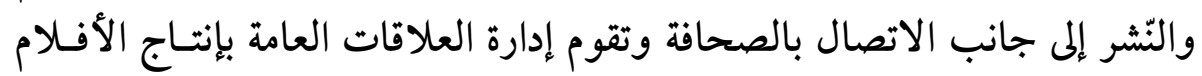

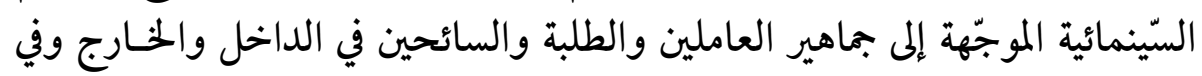
بعض الأحوال تستخدم الصّور والشرائح المضيئة..

ومـن خـلال مـا سـبق يمكـن حصـر وظــائف العلاقـات العامـة في المنشــأة السياحية في نوعين وهما: 
1.وظيفة العلاقات العامة الداخلية : من الواضح أن وظيفة العلاقات العامة هي

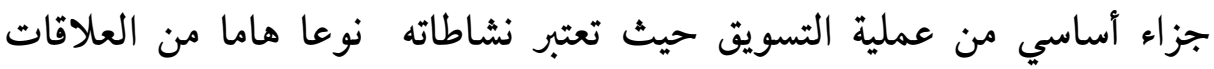

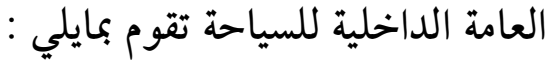
- إعداد الوثائق الخاصة بالسياسات السياحية.

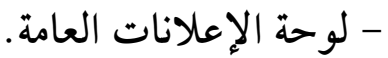

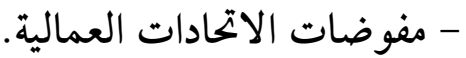

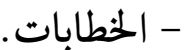

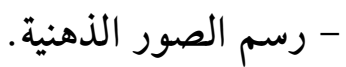
2.وظيفة العلاقات العامة الخارجية

تأخذ هذه الوظيفة عدة أشكال و يمكن استخدامها لعدة أغراض، و توجه

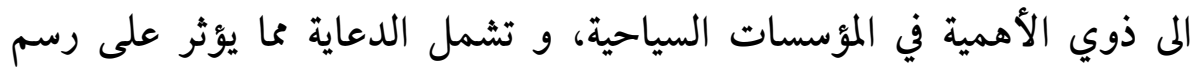

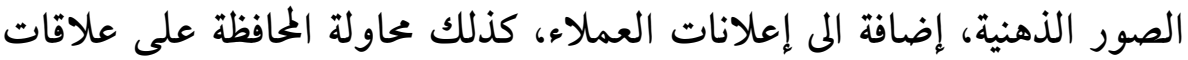
طيبة مع المؤسسات المالية و المؤسسات الاتصالية الماتية المختلفة (52). 


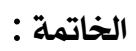

في ختام هذا البحث يمكن القول بان العلاقات العامة هي وظيفة هلا

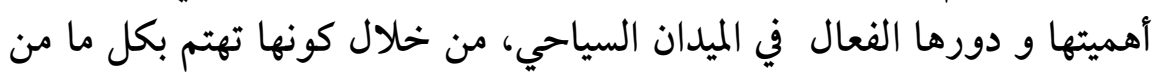

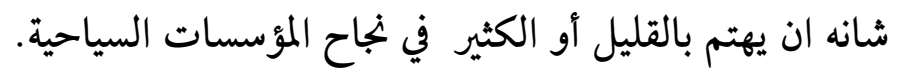

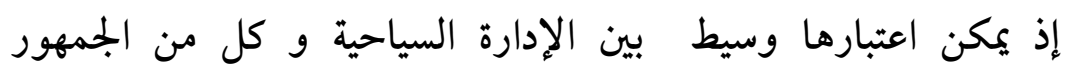

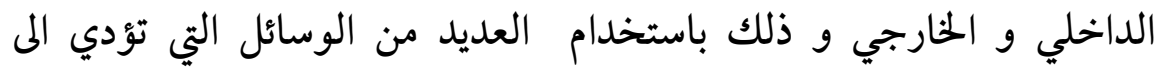

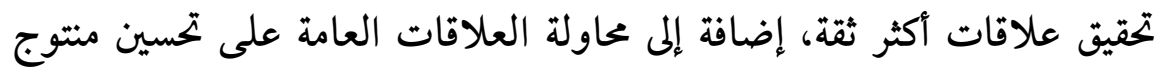

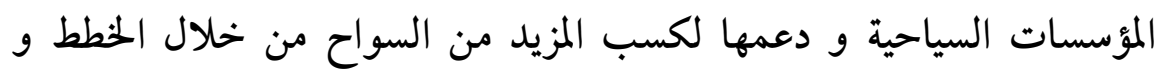
البرامج التي تقوم بإعدادها وفق النظام العالمي المتغير. 


\section{هوامش البحث:}

عبيدة صبطي ،كلثوم مسعودي : مدخل الى العلاقات العامة ، تقديم وإشر اف أ. د.

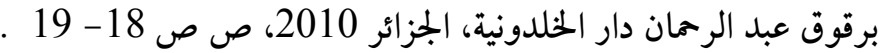
ابن منضور: ليسان العرب، دار صادر، بيروت ، 1997، ص 432 .

أسامة كامل ، محمد العيرفي: إدارة العلاقات العامة، مؤسسة لورد للشؤون العالمية،

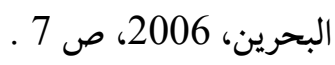

هناء حافظ بدوي: العلاقات العامة و الحدمة الاجتماعية ، المكتب الجامعي الحديث ،

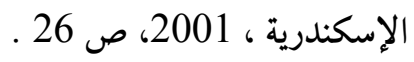

أحمد محمد المصري: العلاقات العلاقات العامة ، مؤسسة شباب الجامعة ، الاسكندرية

$$
\text { 2000، }
$$

محمد عبد الفتاح محمد: العلاقات العامة بمنظمات الرعاية الاجتماعية، ط 3، المكتب

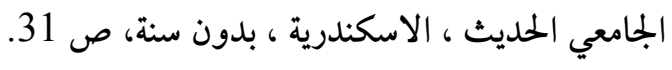

صالح خليل أبو أصبع: العلاقات العامة والاتصال الانساني ، دار الشروق، عمان ، 1998، ص 84.

جبارة عطية جبارة: علم اجتماع الإعلام، دار الوفاء لدينا الطباعة والنشر،

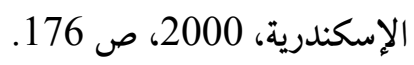

محمد عبد الفتاح محمد، مرجع سابق، ص 33.

راسم محمد الجمال، خيرت معرض عياد: إدارة العلاقات العامة، الدار المصرية

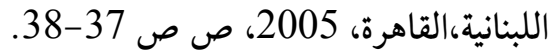

هناء حافظ بدوي: مرجع سبق ذكره، ص411. 
عبد الرزاق محمد الدليمي: العلاقات العامة والعولمة، دار جرير للنشر والتوزيع،

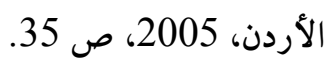

هناء حافظ بدوي: مرجع سبق ذكره، ص ص 41- 42.

صالح خليل أبو أصبع، مرجع سبق ذكره، ص 104.

هناء حافظ بدوي، مرجع سبق ذكره، ص 43.

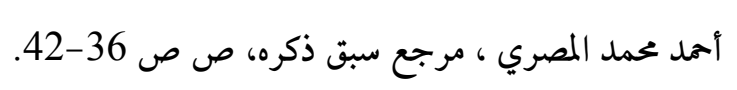

نسمة أمد البطريق: الإعلام و المجتمع في عصر العولمة دراسة في المداخل الاجتماعية،

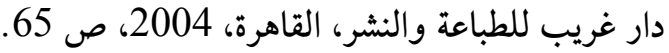

$$
\begin{aligned}
& \text { أمد محمد المصري: مرجع سبق ذكره، ص ص 43-53. }
\end{aligned}
$$

محمد معوض، بركات عبد العزيز: الحبر الإذاعي و التلفزيوني، ط2، دار الكتاب

$$
\text { الحديث، القاهرة، 2000، صوضك بـ } 9 .
$$

$$
\begin{aligned}
& \text { (20) احمد محمد المصري: مرجع سبق ذكره، ص ص 58-60. } \\
& \text { المرجع السابق، ص ص 65-66. } \\
& \text { محمد عبد الفتاح محمد : مرجع سبق ذكره، ص } 224 \\
& \text { المرجع السابق، ص } 226 \text {. } \\
& \text { أحمد محمد المصري :مرجع سبق ذكره، ص } 81 . \\
& \text { محمد عبد الفتاح محمد : مرجع سبق ذكره، ص } 227 . \\
& \text { أحمد محمد المصري:مرجع سبق ذكره ، ص ص 79- } 80 . \\
& \text { محمد عبد الفتاح: مرجع سبق ذكره، ص228. }
\end{aligned}
$$

(28) شدوان علي شيبة: العلاقات العامة بين النظرية والتطبيق، دار المعرفة الجامعية،

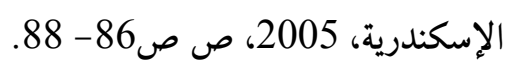




$$
\text { المرجع السابق: ص ص 88- } 91 .
$$

محمد علي محمد: تاريخ علم الاجتماع، دار المعرفة الجامعية، الإسكندرية، 1984،

$$
\begin{aligned}
& \text { شدوان علي شبيه: مرجع سبق ذكره، ص ص } 93 \text { - } 94 . \\
& \text { المرجع السابق: ص ص 97، 98، } 98 . \\
& \text { المرجع السابق: ص ص } 100 .
\end{aligned}
$$

(34) ريان درويش:" الاستثمارات السياحية بالأردن الحصيلة و الافاق، المستقبلية "، رسالة

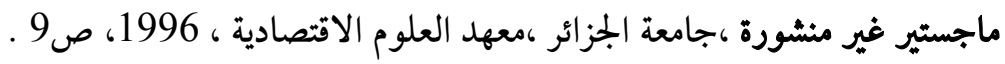
محمود كامل: السياحة الحديثة علما و تطبيقا، دار الفكر الجامعي، الإسكندرية، 1985، صـ13

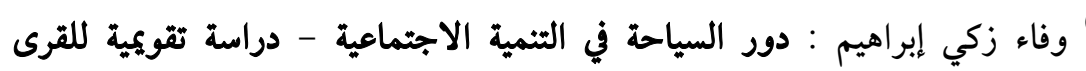

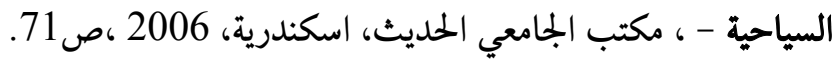

مدي عبد العظيم : اقتصاديات السياحة مدخل نظري و عملي متكامل ، مكتبة

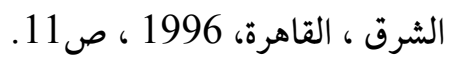
محمد البنا: السياحة وقت الفراغ ، مطابع آلاء الحديثة، القاهرة،1999، ص ص15-

مروان السكر العدوان : الاقتصاد السياحي ، دار مجدلاوي للنشر، عمان، ص13. مروان السكر العدوان: مختارات من الاقتصاد السياحي ، دار مجدلاوي للنشر، عمان

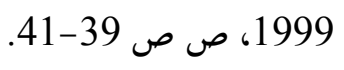

طلعت الدمرداشي ابراهيم : اقتصاديات انشاء المدن الجلديدة ، دار الفكر الجامعي، الاسكندرية، 1998 ، ص ص 130. خالد كواش: مرجع سبق ذكره، ص 54 . 
محمد فوزي مولوخية: مدخل اللى علم السياحة، دار الفكر الجامعي، الاسكندرية،

$$
\text { 2007، صوند فوري }
$$

محمد خميس زوكة : صناعة السياحة من منظور جغرافي، دار المعرفة، الاسكندرية،

$$
2002
$$

محمد خميس زوكة: جغرافية النقل، ط2، دار المعرفة، الاسكندرية، 1995، ص 107.

$$
\text { محمد فوزي مولوخية ، مرجع سبق ذكره، ص } 20 .
$$

محمد خميس زوكة: صناعة السياحة من منظور جغرافي، مرجع سبق ذكره ، ص ص،

محمد منير حجاب: الاتصال الفعال للعلاقات العامة ، دار الفجر للنشر و التوزيع،

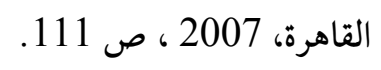

$$
\text { أحمد محمد المصري: مرجع سبق ذكره، ص } 27 .
$$

إبراهيم إمام: فن العلاقات العامة والإعلام، الطبعة الثانية، مكتبة الأنجلو المصرية،

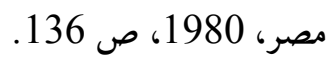

أحمد الجلاد: التنمية والإعلام السياحي المستدام، عالم الكتب، مصر، 2003، ص

خالد مقابلة: الترويج الفندقي الحديث ، دار وائل للطباعة و النشر، عمان، 1999، 